\title{
Experiment Safety Assurance Package for Mixed Oxide Fuel Irradiation in an Average Power Position (I-24) in the Advanced Test Reactor
}

\author{
S. T. Khericha \\ R. C. Howard
}

May 2000

Idaho National Engineering and Environmental Laboratory Bechtel BWXT Idaho, LLC 
INEEL/EXT-2000-01043

DAR No.: MOX-ESAP-3

\title{
Experiment Safety Assurance Package for Mixed Oxide Fuel Irradiation in an Average Power Position (I-24) in the Advanced Test Reactor
}

\author{
S. T. Khericha \\ R. C. Howard \\ Published May 2000 \\ Idaho Falls, Idaho 83415 \\ Prepared for the \\ U.S. Department of Energy \\ Assistant Secretary for \\ Nuclear Energy \\ Under DOE Idaho Operations Office \\ Contract DE-AC07-99ID13727
}

Idaho National Engineering and Environmental Laboratory 
MOX FUEL IRRADLATION ESAP

DAR No.: MOX-ESAP-3 May 2000

\section{EXPERIMENT SAFETY ASSURANCE PACKAGE \\ FOR MIXED OXIDE FUEL IRRADIATION \\ IN AN AVERAGE POWER POSITION (I-24) \\ IN THE ADVANCED TEST REACTOR}

MAY 2000

S. T. Khericha

R. C. Howard

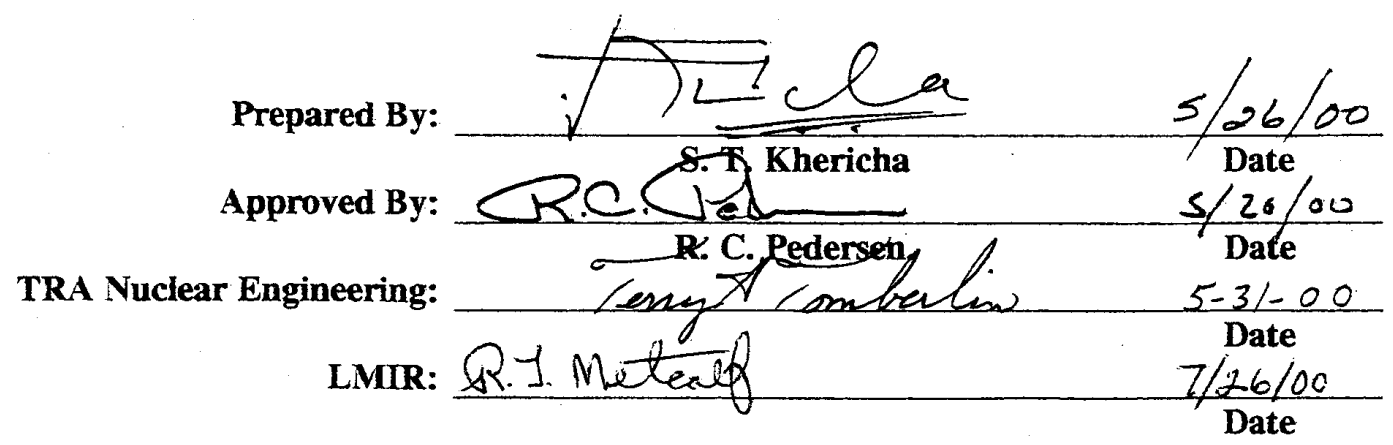




\section{CONTENTS}

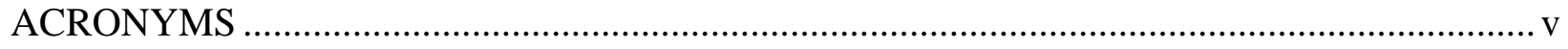

1

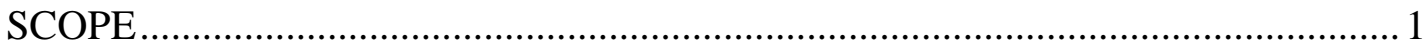

2. CAPSULE ASSEMBLY IDENTIFICATION AND LOADING PATTERN .............. 7

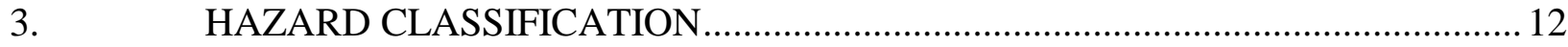

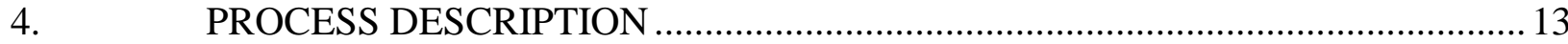

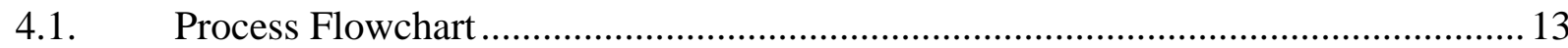

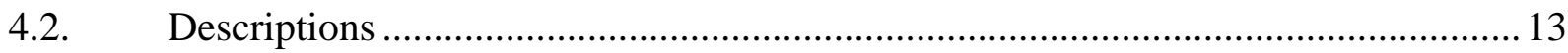

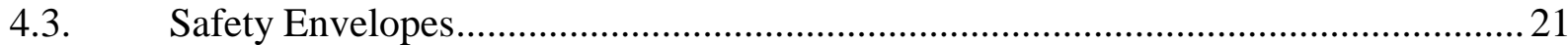

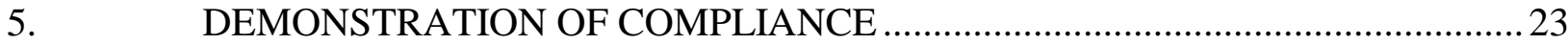

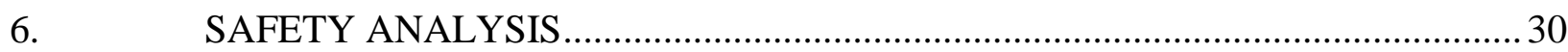

6.1. Assembling of the Test Assembly on the ATR Main Floor ....................................... 30

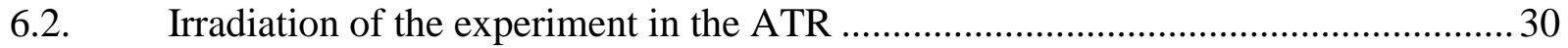

6.2.1. Condition 1 Normal Power Operation in Reactor ................................................ 31

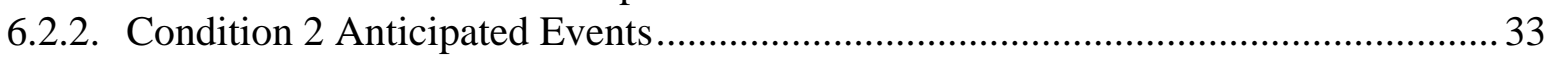

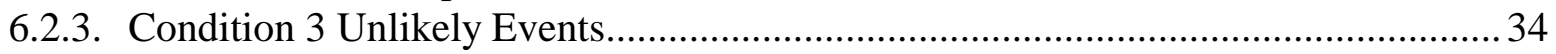

6.2.4. Condition 4 Extremely Unlikely Events .................................................................... 35

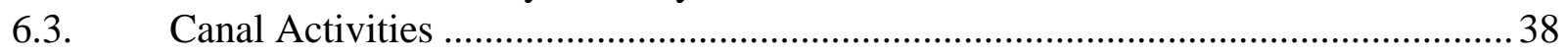

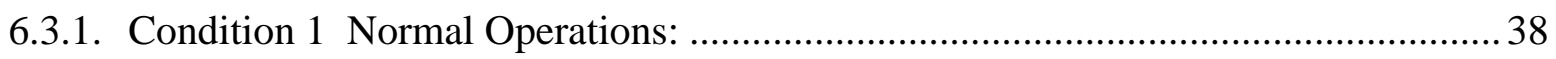

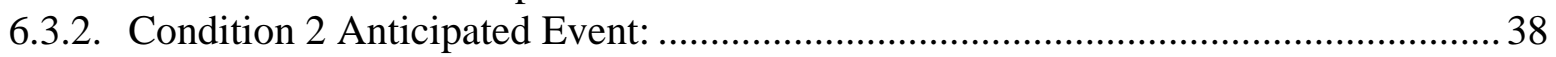

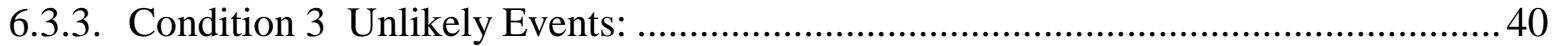

6.3.4. Condition 4 Extremely unlikely events: ................................................................ 41

6.4. Transport of unirradiated or irradiated capsule assemblies within TRA ..................... 41

6.5. Cask Handling and Shipping Activity …………................................................... 42

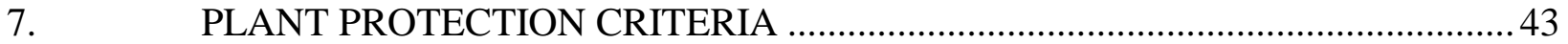

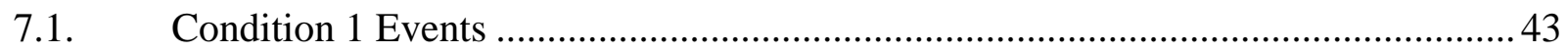

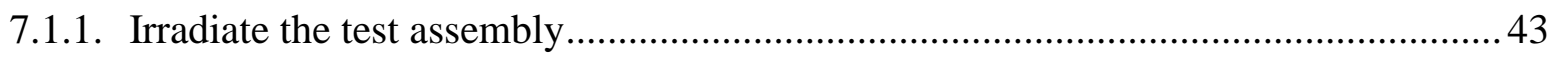

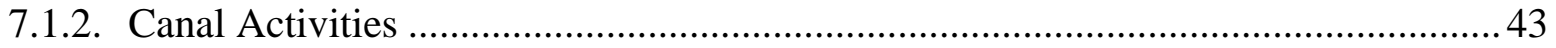

7.1.3. Transfer unirradiated or irradiated MOX fuel and dummy capsule assemblies and basket assembly. ……........................................................................................ 44

7.1.4. Store the irradiated capsule assemblies in the ATR Canal ..........................................4 44

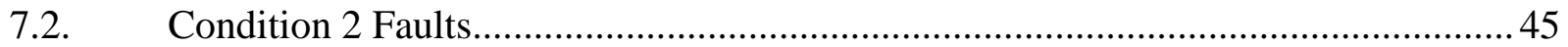

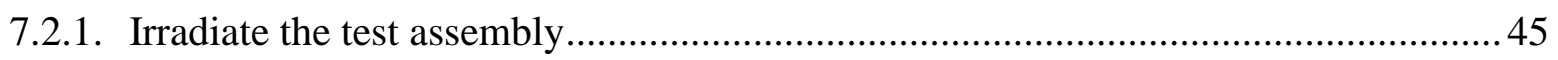

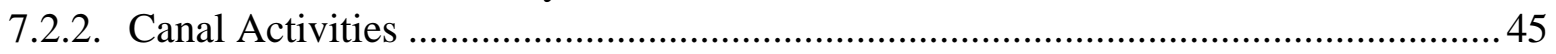

7.2.3. Transport of unirradiated and irradiated capsule assemblies and basket assembly .. 46

7.2.4. Store the irradiated capsule assemblies in the ATR Canal .......................................... 46

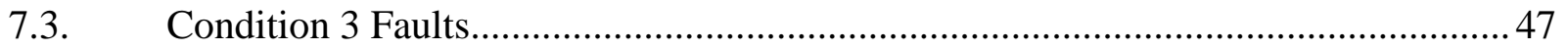

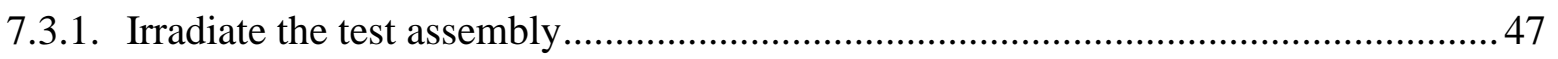

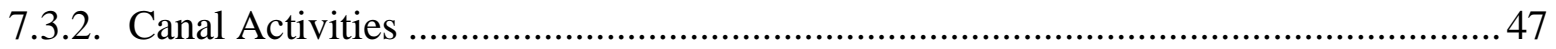

7.3.3. Transport of unirradiated and irradiated capsule assemblies and basket assemblies 48

7.3.4. Store the irradiated capsule assemblies in the ATR Canal ........................................48

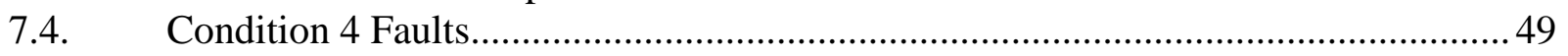

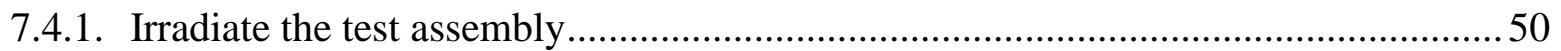

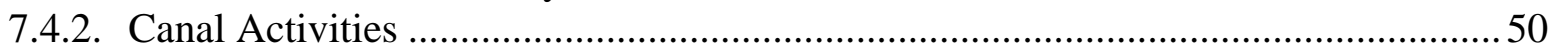


7.4.3. Transport of unirradiated and irradiated capsule assemblies and basket assemblies 51

7.4.4. Store the irradiated capsule assemblies in the ATR Canal ...................................5 51

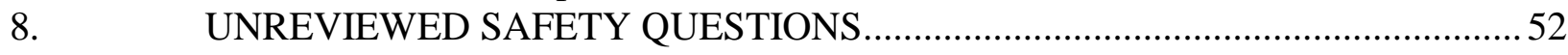

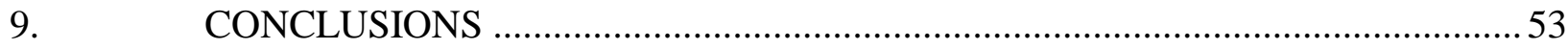

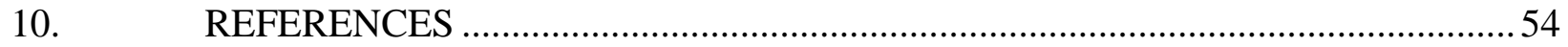

\section{FIGURES}

Figure 1. Cross sectional view of fully assembled MOX capsule.......................................... 4

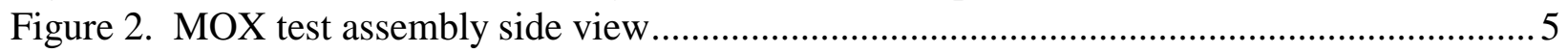

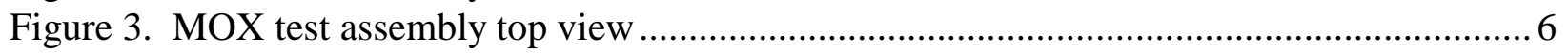

Figure 4. Three phases of MOX fuel irradiation project ..................................................... 9

Figure 5. Suggested initial capsule assembly loading pattern, Phase 1 .................................... 10

Figure 6. Suggested capsule assembly loading pattern, Phase II irradiation............................. 10

Figure 7. Suggested capsule assembly loading pattern for Phase III, Part 1 irradiation.............. 11

Figure 7a. Suggested capsule assembly loading pattern for Phase III, Part 2 irradiation............ 11

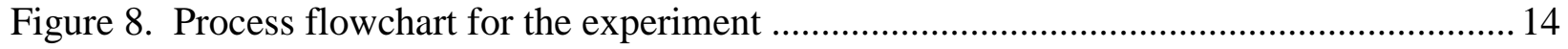

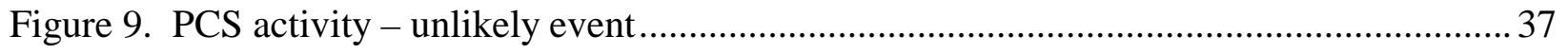

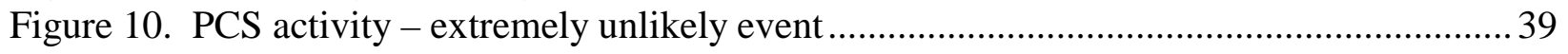

\section{TABLES}

Table 1. Fuel pin assembly to capsule assembly cross-reference.......................................... 8

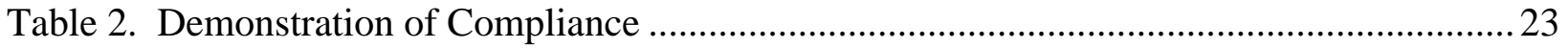




\section{ACRONYMS}

$\begin{array}{ll}\text { ALARA } & \text { As Low As Reasonably Achievable } \\ \text { APT } & \text { Average Power Test } \\ \text { ASME } & \text { American Society of Mechanical Engineers } \\ \text { ATR } & \text { Advanced Test Reactor } \\ \text { ATRC } & \text { Advanced Test Reactor Critical Facility } \\ \text { CAM } & \text { Constant Air Monitor } \\ \text { CCA } & \text { Criticality Control Area } \\ \text { DBR } & \text { Design Basis Report } \\ \text { DNBR } & \text { Departure from Nucleate Boiling Ratio } \\ \text { DOE } & \text { Department of Energy } \\ \text { DOP } & \text { Detailed Operating Procedure } \\ \text { DOT } & \text { Department of Transportation } \\ \text { EOC } & \text { End Of Cycle } \\ \text { ESAP } & \text { Experiment Safety Assurance Package } \\ \text { FIR } & \text { Flow Instability Ratio } \\ \text { GE } & \text { General Electric } \\ \text { GWd/MT } & \text { GigaWatt Days per Metric Ton } \\ \text { HCC } & \text { Hot Cell Carrier } \\ \text { HCF } & \text { Hot Cell Facility } \\ \text { INEEL } & \text { Idaho National Engineering \& Environmental Laboratory } \\ \text { LANL } & \text { Los Alamos National Laboratory } \\ \text { LHGR } & \text { Linear Heat Generation Rate } \\ \text { LMITCO } & \text { Lockheed Martin Idaho Technologies Company } \\ \text { LWR } & \text { Light Water Reactor } \\ \text { MCP } & \text { Management Control Procedure } \\ \text { MOX } & \text { Mixed Uranium and Plutonium Oxide } \\ \text { NRC } & \text { Nuclear Regulatory Commission } \\ \text { ORNL } & \text { Oak Ridge National Laboratory } \\ \text { O\&MM } & \text { Operation and Maintenance Manual } \\ \text { PCS } & \text { Primary Coolant System } \\ \text { PPS } & \text { Plant Protective System } \\ \text { RAM } & \text { Remote Area Monitor } \\ \text { RCT } & \text { Radiation Control Technician } \\ \text { RPSP } & \text { Reactor Programs Standard Practice } \\ \text { RWP } & \text { Radiological Work Permit } \\ \text { SORC } & \text { Safety and Operations Review Committee } \\ \text { SSC } & \text { Systems, Structures and Components } \\ \text { TIGR } & \text { Thermally Induced Gallium Removal } \\ \text { TRA } & \text { Test Reactor Area } \\ \text { TSR } & \text { Technical Safety Requirements } \\ \text { UFSAR } & \text { Upgraded Final Safety Analysis Report } \\ & \end{array}$




\section{SCOPE}

The existing Mixed Oxide (MOX) Fuel Experiment has been irradiated in the Advanced Test Reactor (ATR) under the Fissile Material Disposition Program, Light Water Reactor Mixed Oxide Fuel Irradiation Test Project. The original goal was that when any capsule assembly approaches a burnup of $\sim 30 \mathrm{GWd} / \mathrm{MT}$, the irradiation of all MOX capsule assemblies in the ATR would be terminated. In February 2000, Oak Ridge National Laboratory (ORNL), a lead laboratory on this Project, decided to continue the irradiation of three lowest burnup assemblies (with a maximum burnup of $26 \mathrm{GWd} / \mathrm{MT}$ ) to a burnup of $\sim 30 \mathrm{GWd} / \mathrm{MT}$ (not to exceed 30 $\mathrm{GWd} / \mathrm{MT}$ ) (Cowell 2000). This phase of the experiment includes moving the capsule assemblies to appropriate locations within the test assembly to achieve desired burnup and is referred to as the 'Burnup Equalization Phase'. The purpose of this ESAP is to demonstrate the safe irradiation and handling of the MOX Fuel APT experiment as required by ATR Technical Safety Requirement (TSR) 3.9.1 (ATR 1998). This ESAP also addresses the specific operation of the MOX Fuel APT experiment with respect to the operating envelope for irradiation established by the Upgraded Final Safety Analysis Report (UFSAR) (ATR 1999). Experiment handling activities are discussed herein.

The Fissile Material Disposition Program Light Water Reactor Mixed Oxide Fuel Irradiation Test Project Plan details a series of irradiation tests designed to investigate the use of weaponsgrade plutonium in MOX fuel for light water reactors (LWR) (Cowell 1996a, Cowell 1997a, Thoms 1997a). Commercial MOX fuel has been successfully used in overseas reactors for many years, however, weapons-derived test fuel contains small amounts of gallium (about 1 to 3 parts per million) (Morris 2000). A concern exists that the gallium may migrate out of the fuel and into the clad, inducing embrittlement. For preliminary out-of-pile experiments, Wilson (1997) states that intermetallic compound formation is the principal interaction mechanism between zircaloy cladding and gallium. This interaction is very limited by the low mass of gallium, so problems are not expected with the zircaloy cladding, but an in-pile experiment is needed to confirm the out-of-pile experiments. Ryskamp (1998) provides an overview of this experiment and its documentation.

To provide assurance that the weapons grade MOX fuel will not cause problems to commercial reactors, a set of MOX fuel capsules will be irradiated in the ATR to burnups of approximately 8 to $30 \mathrm{GWd} / \mathrm{MT}$. The ATR is located at the Idaho National Engineering \& Environmental Laboratory (INEEL). The guiding document is Wachs (1997).

The following nomenclature will be used throughout this document and is consistent with that adopted by the project.

Fuel pellet - individual pieces of ceramic MOX fuel composed of $95 \% \mathrm{UO}_{2}$ and $5 \% \mathrm{PuO}_{2}$ (with characteristics very similar to commercial $\mathrm{UO}_{2}$ fuel). See Chidester (1998) for the best estimates of plutonium/uranium masses and isotopics.

Fuel pin assembly - Zircaloy-4 tube with welded end caps containing a stack of 15 fuel pellets and a spring. 
Capsule assembly - stainless steel tube with welded end caps containing a fuel pin assembly (See Figure 1).

Basket assembly (Model-1) - aluminum insert with attached Inconel neutron shield for the ATR I-hole.

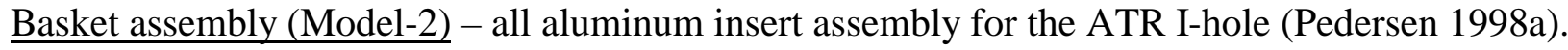

Test assembly - basket assembly with up to nine MOX capsule assemblies (a total of about $35 \mathrm{~g}$ $\mathrm{Pu}$ ) and flux wires (See Figures 2 and 3).

The gaps in the fuel pin and capsule assemblies are filled with helium gas at $1 \mathrm{~atm}$.

As the first phase of the project, Los Alamos National Laboratory (LANL) sent 13 fuel pin

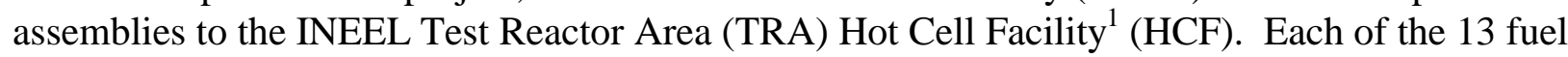
pin assemblies was seal welded in a 304L stainless steel ASME Boiler and Pressure Vessel Code, Section III outer tube. Each weld was radiographed in the Radiography facility (TRA-635) also located at the TRA. A test assembly containing nine of these 13 capsule assemblies was inserted in a small I-hole in the ATR reflector. After the capsule assembly with highest burnup has achieved the targeted burnup of $8 \mathrm{GWd} / \mathrm{MT}$, two capsule assemblies will be removed from the test assembly. The remaining seven irradiated capsule assemplies, along with two unirradiated capsule assemblies, will be reconfigured in the test assembly. ${ }^{2}$ The reconfigured test assembly will then be irradiated until the capsule assembly with highest burnup has achieved the targeted burnup of $20 \mathrm{GWd} / \mathrm{MT}$. Two capsule assemblies will then be removed from the test assembly. The remaining seven irradiated capsule assemblies, along with two dummy capsule assemblies, will be reconfigured in the test assembly. The reconfigured test assembly will then be irradiated until the highest burnup capsule assembly has achieved the total targeted burnup of $30 \mathrm{GWd} / \mathrm{MT}$.

In the equalization of burnup phase, four capsule assemblies with the highest burnup will be removed from the test assembly. Two of these capsule assemblies with the highest burnup will be shipped to ORNL, while two capsule assemblies will be stored in the ATR canal. The remaining three irradiated capsule assemblies, along with six dummy capsule assemblies, will be reconfigured in the test assembly using the same basket assembly. The reconfigured test assembly will then be irradiated until any capsule assembly approaches a total targeted burnup of approximately $30 \mathrm{GWd} / \mathrm{MT}$ (not to exceed $30 \mathrm{GWd} / \mathrm{MT}$ ). The capsule assemblies and the basket assembly will be stored in the ATR canal until the decision is made to irradiate further, or to return all the capsule assemblies and associated hardware to ORNL.

\footnotetext{
International Isotopes of Idaho Incorporated, formally known as Mac Isotopes LLC., has the responsibility of operating the Hot Cell Facility. In Phase II and Phase III, the reconfigured test assembly is expected to use the Model-2 basket. The Model-1 basket assembly used in Phase I could be used again if requested by the customer. Neutronic analyses for both models have been performed by Chang (1998b), and both are found to be satisfactory.

The decision to extend the burnup of the MOX capsule assemblies will be made after the PIE data of the previously irradiated capsule assemblies (@30 GWd/MT burnup) have been evaluated and analyzed for a potential deformation due to pellet swelling and thermal expansion as a result of extended burnup. It is expected that the PIE data and additional analysis will be available by the end of July 2000 . If the decision is made to extend the burnup, Phase IV of the MOX experiment, a new ESAP will be issued
} 
MOX FUEL IRRADIATION ESAP

DAR No.: MOX-ESAP-3 May 2000

Thirteen fuel pin assemblies were received in December 1997. (The project actually started with preliminary/design work in 10/96.) Eleven capsule assemblies are to be irradiated at nearprototypic, average commercial LWR linear heat generation rates (LHGR) of 6 to $10 \mathrm{~kW} / \mathrm{ft}$ to burnup levels of approximately 8 to $30 \mathrm{GWd} / \mathrm{MT}$. Once the capsule assemblies have cooled enough to be shipped, they will be sent to Oak Ridge National Laboratory (ORNL) for postirradiation examination. 
MOX FUEL IRRADIATION ESAP

DAR No.: MOX-ESAP-3 May 2000

Figure 1. Cross sectional view of fully assembled MOX capsule

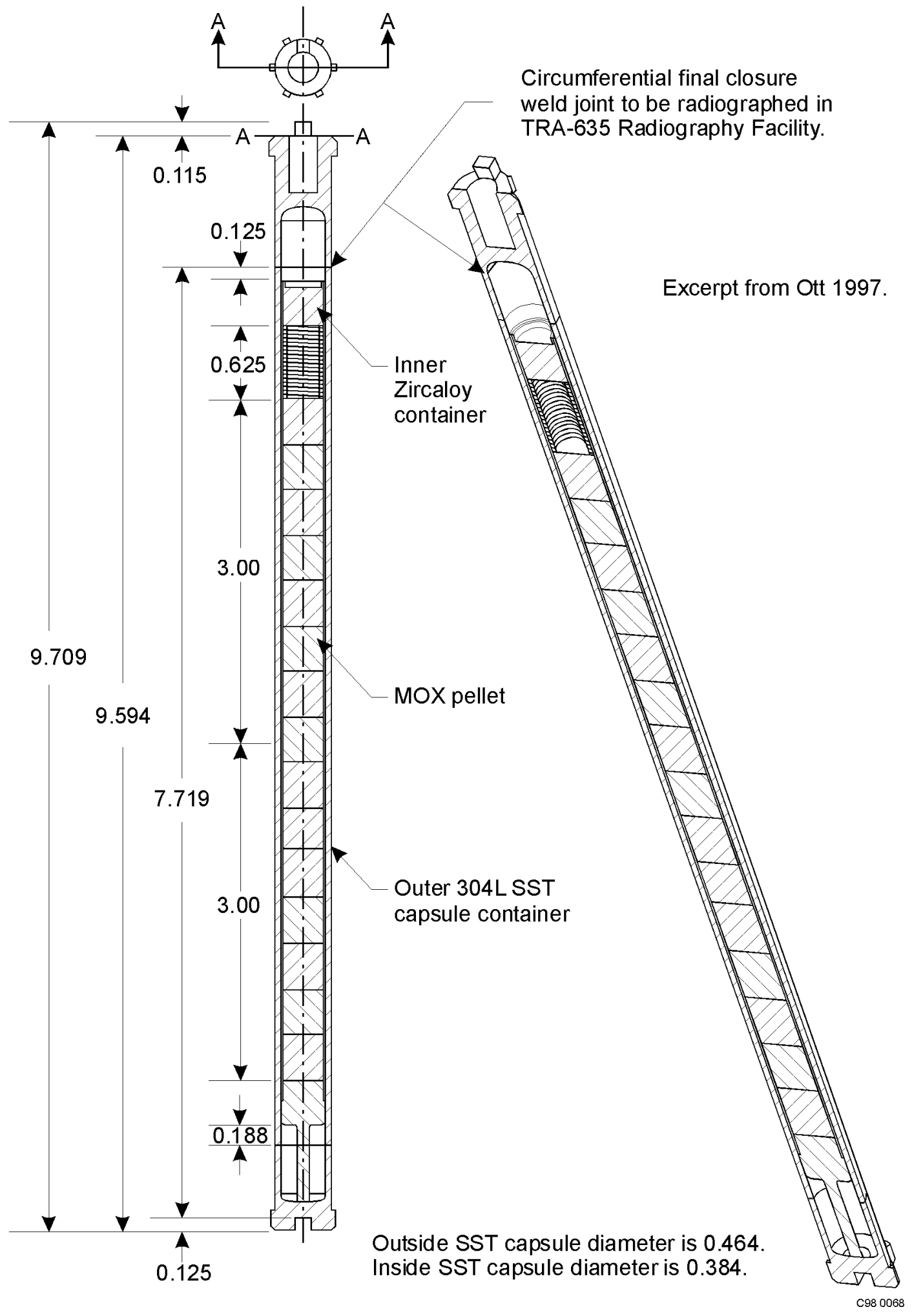




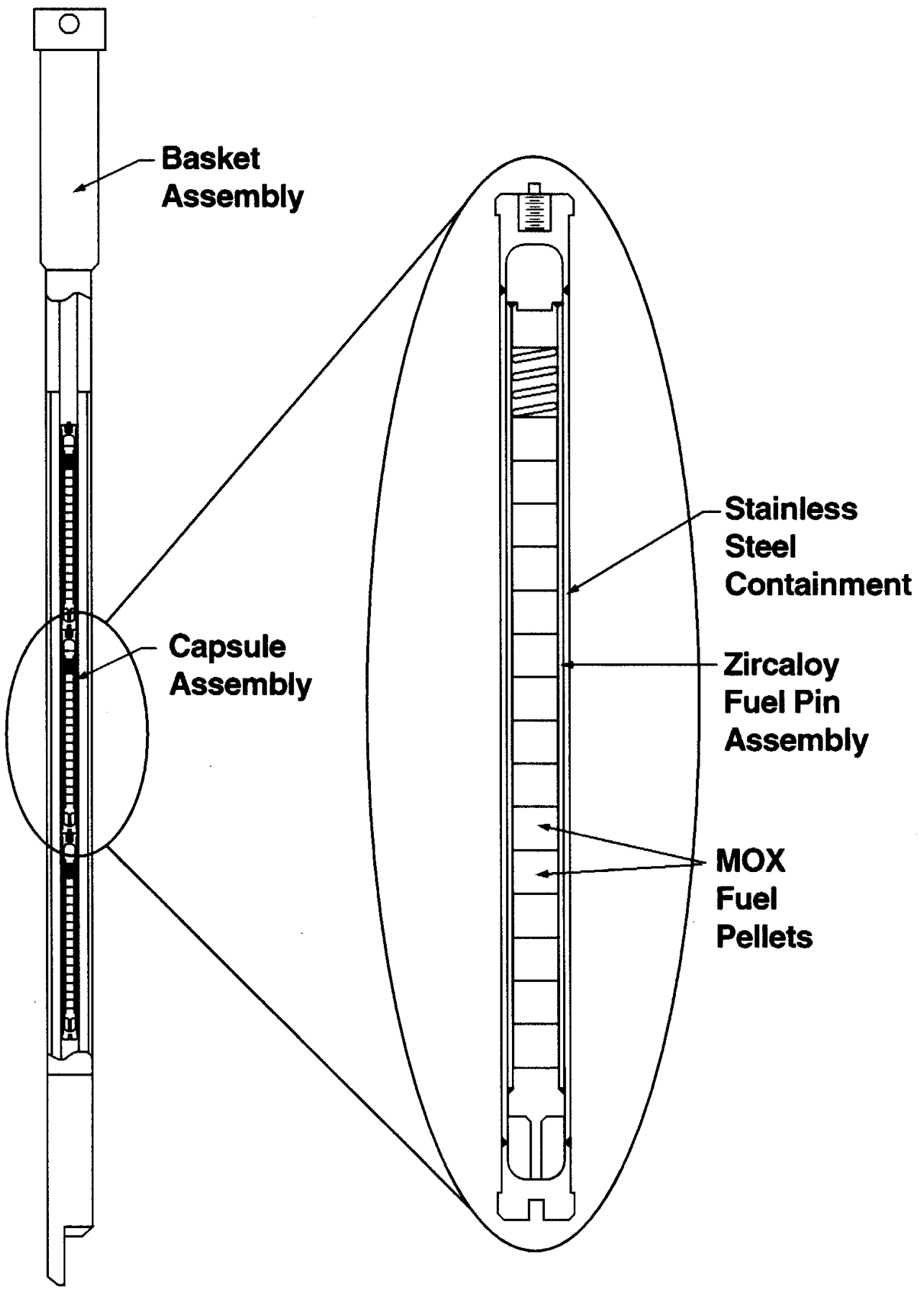

Test Assembly

Capsule Assembly

Figure 2. MOX test assembly side view 
Figure 3. MOX test assembly top view

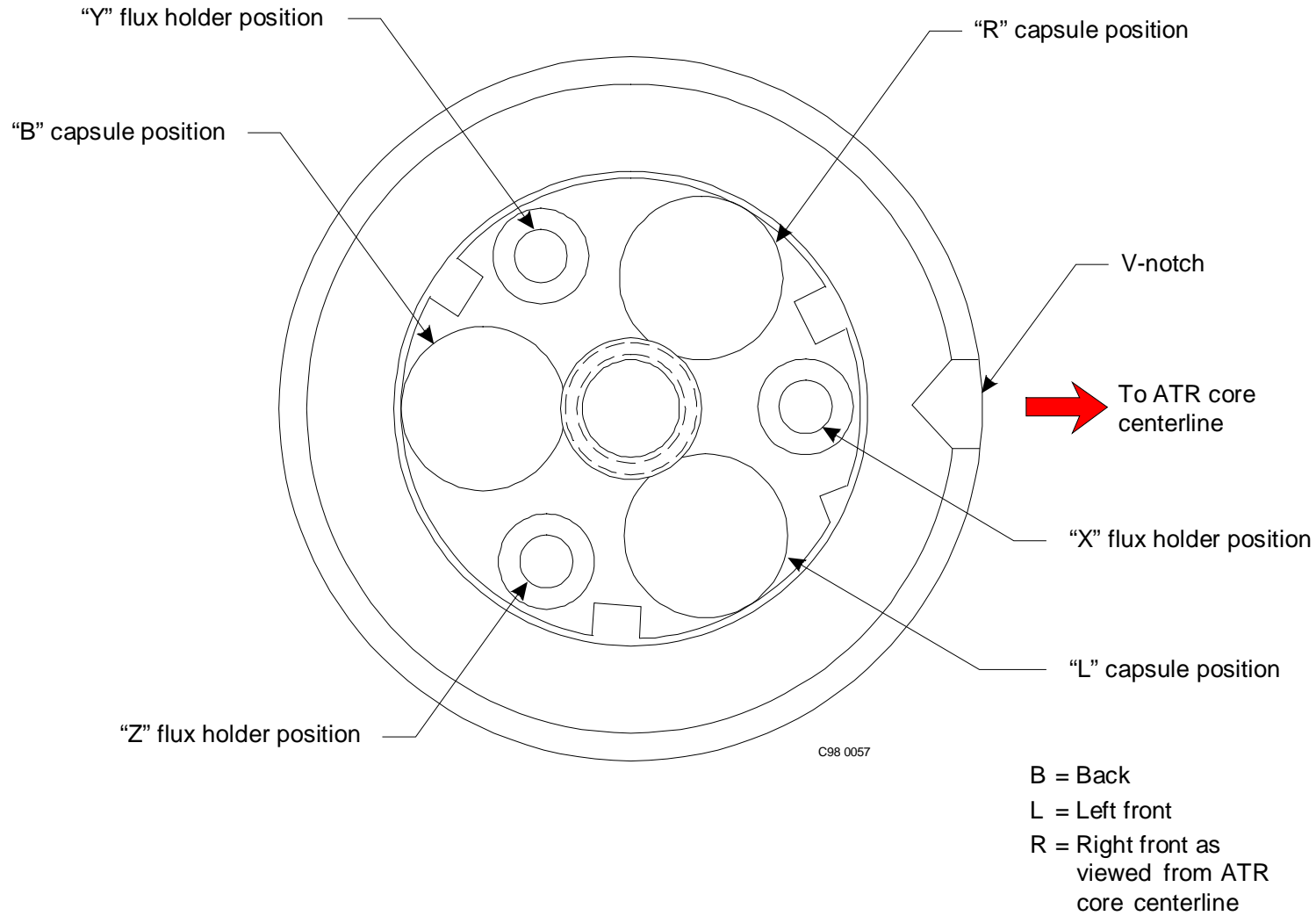


MOX FUEL IRRADIATION ESAP

DAR No.: MOX-ESAP-3 May 2000

\section{CAPSULE ASSEMBLY IDENTIFICATION AND LOADING PATTERN}

The capsule assemblies to be used for this project are numbered 1-13, as shown in Table 1. The capsule assemblies are uniquely marked with identification marks drilled into the top end cap that are readable under water, as shown in Figure 2. (Cowell 1997b). The first seven capsule assemblies contain MOX fuel fabricated from plutonium that has not been treated for gallium removal. The remaining six capsule assemblies contain MOX fuel fabricated from plutonium that has been thermally treated (via the Thermally Induced Gallium Removal (TIGR) process under development at LANL) for gallium removal.

The experiment consists of three irradiation phases as shown in Figure 4 (Cowell 1997c). Eleven capsule assemblies are to be irradiated. Nine capsules were loaded in the initial insertion in Phase I. In Phase II, two spare capsule assemblies were loaded after the first withdrawal of two capsule assemblies.

In Phase III, Part 1, two dummy capsule assemblies (solid 304L stainless steel) were loaded after the withdrawal of another two MOX capsule assemblies. The loading pattern is designed to expose pairs of capsule assemblies, one from each fuel type, to similar irradiation conditions throughout all three irradiation phases by taking advantage of axial and radial symmetry to the extent possible. In Phase III, Part 2 (also referred to as Burnup Equalization Phase), the four capsule assemblies with the highest burnup will be removed from the test assembly. Two capsule assemblies with the highest burnup will be returned to ORNL and the remaining two capsule assemblies will be stored in the ATR canal. The remaining three irradiated capsule assemblies, along with six dummy capsule assemblies (four new dummy capsule assemblies and two irradiated dummy capsule assemblies), will be reconfigured in the test assembly. The loading pattern is designed to approach equal burnups of these three assemblies while remaining under $30 \mathrm{GWd} / \mathrm{MT}$. The reconfigured test assembly will then be irradiated until any capsule assembly approaches a total targeted burnup of approximately $30 \mathrm{GWd} / \mathrm{MT}$. The capsule assemblies and the basket assembly will be stored in the ATR canal until the decision is made to further irradiate or to return all the capsule assemblies and associated hardware to ORNL.

The basket assembly is designed with an anti-rotation locating device that will ensure placement of the basket assembly in the I-hole such that two of the three fuel channels are located equidistant from the core axial centerline (left and right), with the third channel located slightly farther away (back). As viewed from the core centerline, these three fuel channels will hereafter be referred to individually as left, right, and back (L, R, and B are shown on Figure 3). Three individual capsule assemblies will be stacked in each of the three channels. These locations are herein designated as the top, middle, and bottom positions.

Because Capsules 1-7 are all type A fuel, they can be placed in any assembly position that requires type A fuel. Likewise, capsules $8-13$ can be placed in any assembly position that requires type $\mathrm{B}$ fuel.

\footnotetext{
${ }^{4}$ In the case of extended burnup beyond $30 \mathrm{GWd} / \mathrm{MT}$, a new ESAP document will be issued.
} 
MOX FUEL IRRADIATION ESAP

DAR No.: MOX-ESAP-3 May 2000

Table 1. Fuel pin assembly to capsule assembly cross-reference.

\begin{tabular}{|c|c|c|c|}
\hline $\begin{array}{l}\text { Capsule Assembly } \\
\text { Number }\end{array}$ & $\begin{array}{l}\text { Fuel Assembly } \\
\text { Number }\end{array}$ & Fuel Batch & Gallium Treatment \\
\hline 1 & 2 & $\mathrm{~A}$ & None \\
\hline 2 & 5 & A & None \\
\hline 3 & 6 & A & None \\
\hline 4 & 7 & A & None \\
\hline 5 & 8 & A & None \\
\hline 6 & 9 & A & None \\
\hline 7 & 10 & A & None \\
\hline 8 & 11 & B & Thermal (TIGR) \\
\hline 9 & 12 & B & Thermal (TIGR) \\
\hline 10 & 13 & B & Thermal (TIGR) \\
\hline 11 & 14 & B & Thermal (TIGR) \\
\hline 12 & 15 & B & Thermal (TIGR) \\
\hline 13 & 16 & B & Thermal (TIGR) \\
\hline
\end{tabular}

Irradiation Phase I extends from the initial insertion until the capsule assembly with highest burnup reaches an average burnup of $8 \mathrm{GWd} / \mathrm{MT}$. The loading pattern used for Phase I is shown in Figure 5 (Cowell 1997c).

Irradiation Phase II extends until the capsule assembly with highest burnup reaches an average burnup of $20 \mathrm{GWd} / \mathrm{MT}$. A suggested loading pattern to be used for Phase II is shown in Figure 6 (Cowell 1997c). The ORNL project management will select the actual loading pattern. From the ATR safety standpoint, all capsules are identical and can be placed in any position.

Irradiation Phase III, Part 1 extends from the end of Phase II until the capsule assembly with highest burnup reaches $30 \mathrm{GWd} / \mathrm{MT}$. A suggested loading pattern to be used in Phase III, Part 1 is shown in Figure 7 (Cowell 1997c). The loading pattern to be utilized for Phase III, Part 1 of the irradiation leaves the two highest-flux positions (middle left and middle right) filled with dummy capsule assemblies rather than MOX-bearing capsule assemblies. This placement is expected to increase the power production in the capsule assembly located in the middle, back position (i.e., Capsule Assembly 5), but it will have negligible impact on the remainder of the capsule assemblies.

Irradiation Phase III, Part 2 extends from the end of Phase III, Part 1, until any capsule assembly approaches a total targeted burnup of $\sim 30 \mathrm{GWd} / \mathrm{MT}$. A suggested loading pattern to be used in Phase III, Part 2 is shown in Figure 7a (Cowell 2000). This loading pattern leaves the highestflux positions (middle left, right, and back ) filled with three capsule assemblies. The remaining six positions (top and bottom positions in all three locations) will be filled with dummy capsule assemblies. This placement is expected to approach equal burnups of these irradiated capsule assemblies.

Externally, the dummy capsule assemblies will be identical to the fueled assemblies, such that hydraulic flow conditions in the test assembly are not significantly affected. Each dummy capsule assembly will be a solid piece of stainless steel 304L. 
MOX FUEL IRRADIATION ESAP

DAR No.: MOX-ESAP-3 May 2000

Figure 4. Three phases of MOX fuel irradiation project

Phase I

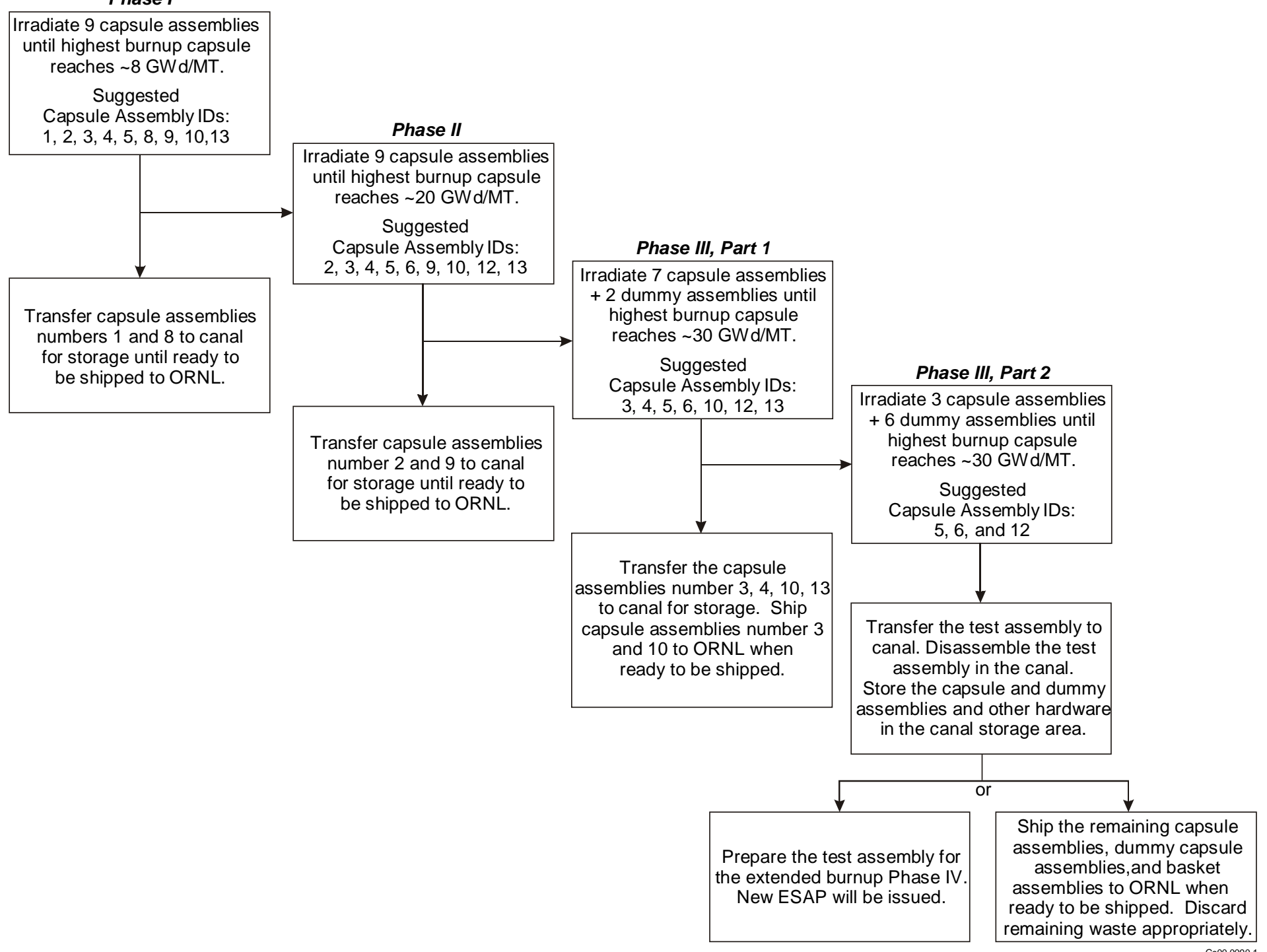




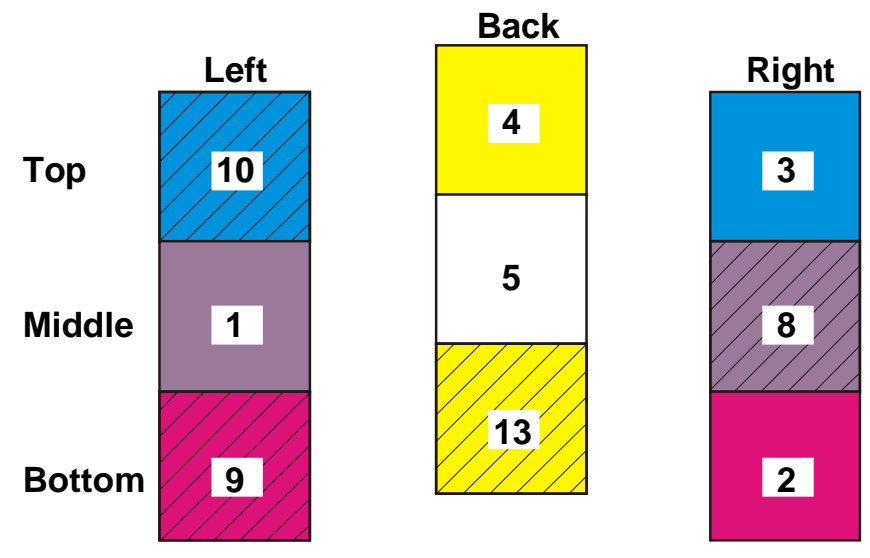

$\mathrm{N}=$ Capsule Assembly Identification Number

Figure 5. Suggested initial capsule assembly loading pattern, Phase 1.

Figure 6. Suggested capsule assembly loading pattern, Phase II irradiation.

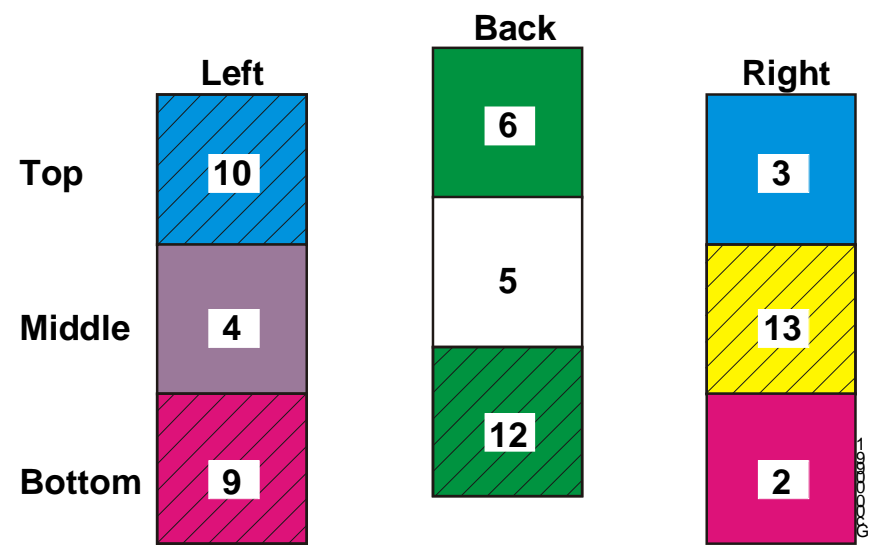

$\mathrm{N}$ = Capsule Assembly Identification Number 
Figure 7. Suggested capsule assembly loading pattern for Phase III, Part 1 irradiation.

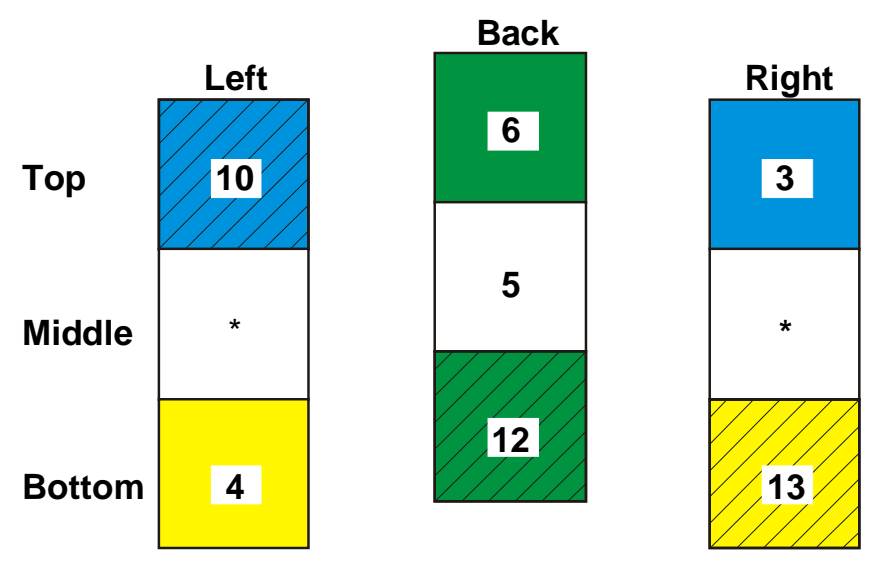

$\mathrm{N}$ = Capsule Assembly Identification Number $\square=$ Dummy Capsule Assembly

Figure 7a. Suggested capsule assembly loading pattern for Phase III, Part 2 irradiation.

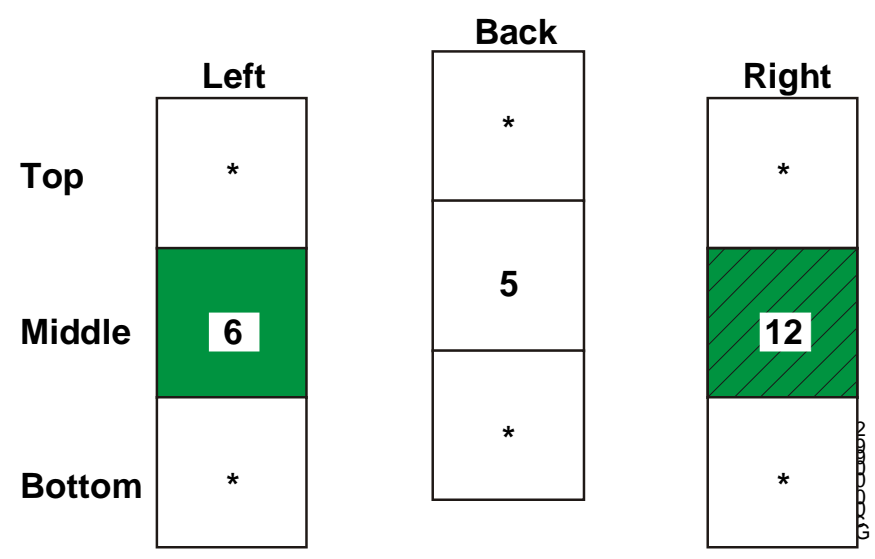

$\mathrm{N}$ = Capsule Assembly Identification

$\triangle=$ Dummy Capsule 
MOX FUEL IRRADIATION ESAP

DAR No.: MOX-ESAP-3 May 2000

\section{HAZARD CLASSIFICATION}

The ATR and its activities have been classified as Hazard Category 1 per DOE Order 5480.23 (DOE 1992a). The introduction of the MOX fuel experiments into ATR does not change the hazard classification.

Two unirradiated MOX fuel capsule assemblies (\#6 and \#12) will be transported from the TRA Plug Storage Area North to the ATR Canal in a DOT Type B fissile material transport package consisting of a 10 gallon DOT Specification 6M drum, with DOT Specification 2R inner containment vessel. Transport will be in compliance with RPSP 10.6.4.6, "TRA Unirradiated Fissile Material Control." The two MOX fuel capsule assemblies contain a total of approximately $7.2 \mathrm{~g}$ of accountable plutonium (Pu-239/241), approximately $0.4 \mathrm{~g}$ accountable uranium (U-235), and approximately $0.4 \mathrm{~g}$ of non-accountable plutonium (Pu-240). DOE-STD1027-92 (DOE 1992b) allows materials in DOT Type B shipping containers to be excluded from a facility's radioactive inventory. Therefore, credit can be taken for the DOT Type B shipping container when considering the hazard classification associated with the transport. Transporting the two unirradiated MOX fuel capsule assemblies would constitute a Hazard Category 3 activity if no credit was applied for shipment in the DOT Type B shipping container (Khericha 1998).

Unirradiated dummy capsule assemblies will be received in the canal area. The unirradiated dummy capsule assemblies will be transported by routine methods since they are not large, heavy, radioactive, or hazardous.

The Hazard Category for the transfer of two irradiated MOX capsule assemblies in Hot Cell Carrier (HCC) \#3 has been determined to be Hazard Category 3 (Pedersen 1998b). Reference approves the HCC \#3 for Category 3 transport. Hazards associated with MOX experiment materials shipped in the GE-100 and GE-2000 casks are maintained within the qualifications of these DOT/NRC approved shipping containers. Preliminary hazard identifications and classifications of these types of shipments are addressed in Sections 5.2 of Reference NFACOSB 1996. 


\section{PROCESS DESCRIPTION}

\subsection{Process Flowchart}

Figure 8 shows the "cradle-to-grave" process flowchart for the MOX APT. For this experiment, "cradle-to-grave" includes the experiment transfer from the Hot Cell Facility at the TRA until all the capsules leave the TRA main gate.

This ESAP is prepared on the basis that initial irradiation will take place in the ATR reflector location small I-24 hole in order to achieve programmatic desired LHGR's in the range of 6-10 $\mathrm{kW} / \mathrm{ft}$. The safety analysis allows operation up to $12 \mathrm{~kW} / \mathrm{ft}$. A physics calculation will be performed before the start of every cycle to determine if the LHGR in each capsule assembly meets the programmatic and safety objectives (Chang 1998a, 1998b). The explanation of the steps and associated governing documents, where applicable, are detailed in Section 4.2.

\subsection{Descriptions}

Steps A through XA were executed in Phase I, Phase II, and Phase III, Part 1. Steps E through I were executed in Phase I, Phase II, and Phase III, Part 1 but will be repeated as necessary and are listed for completeness.

Step E Irradiate the test assembly

The test assembly will be irradiated for a cycle in the reactor.

Step F Transfer the test assembly to the ATR Canal after a cycle

The test assembly will be removed from the I-24 reactor core position, inserted into a transfer bucket and transferred to the canal per DOP 7.2.17.

Step G Replace the test assembly flux monitors

Remove the flux wires from the test assembly in the canal and place the flux wires in the canal MOX flux wire storage bucket. The RML Laboratory personnel will count flux wires in the ATR canal. Specifically designed tools for the MOX experiment will be used. After the counting, the flux wires will be put in the canal waste stream.

Install new flux wires in the basket assembly using tools specifically designed for it, in accordance with current methodology and using existing procedures. 
Figure 8. Process flowchart for the experiment

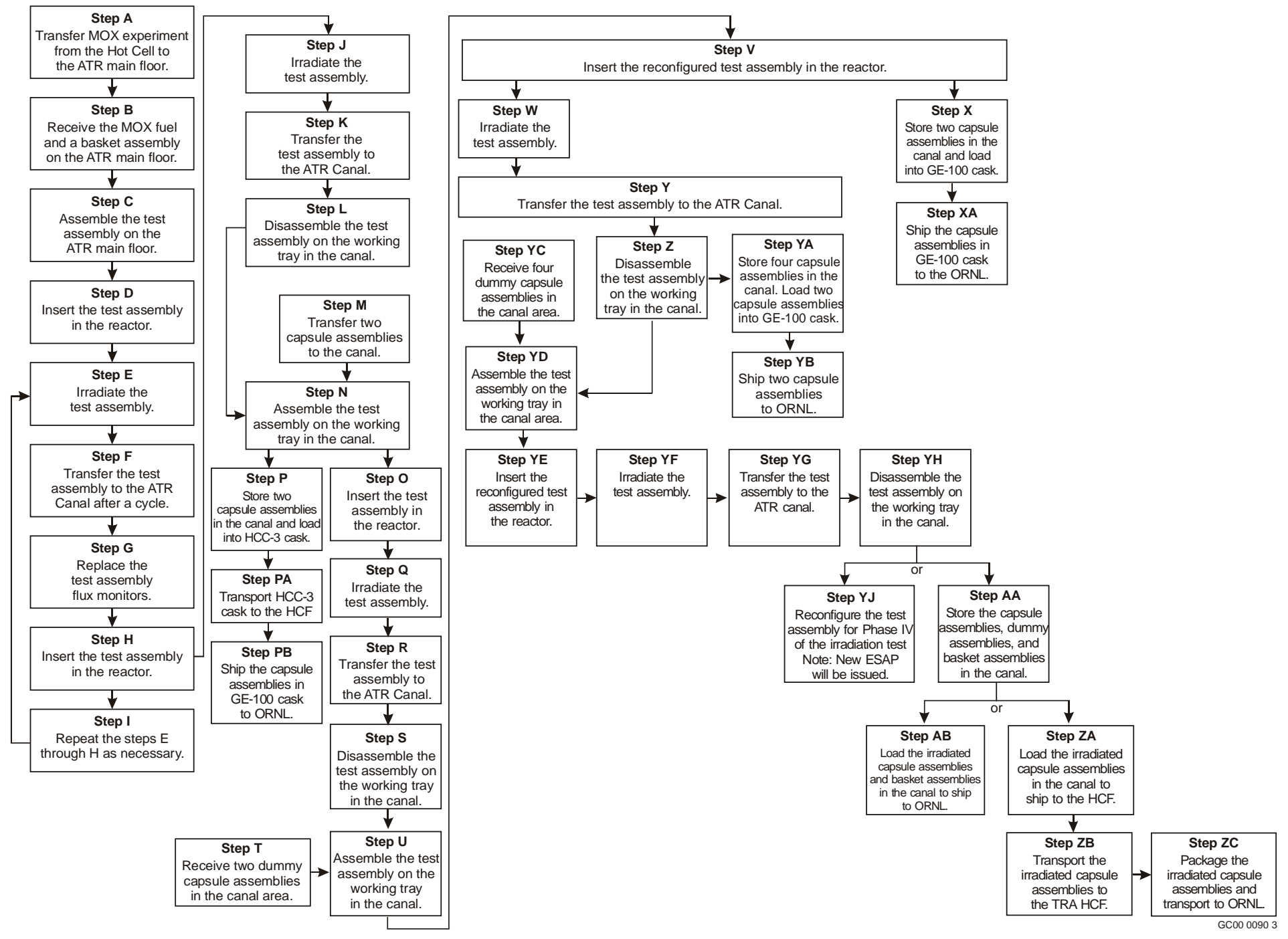


Step $\mathrm{H}$ Insert the test assembly in the reactor

The experiment assembly will be transferred to the reactor under existing O\&MM's and inserted in the reactor location I-24 hole by DOP 7.2.17.

Step I Repeat the steps E through $\mathrm{H}$ as necessary

Steps $\mathrm{E}$ through $\mathrm{H}$ will be repeated as necessary until such time as neutronic burnup calculations have been shown to satisfy MOX programmatic requirements and no longer need the flux wire measurements.

Step J Irradiate the test assembly

The test assembly will be irradiated in the reactor. The test assembly will remain in the reactor position until the highest burnup capsule assembly has reached desired burnup of $8 \mathrm{GWd} / \mathrm{MT}$. Preliminary depletion calculations indicate that 7 to 9 calendar months of irradiation will be required to achieve an average burnup of $8 \mathrm{GWd} / \mathrm{MT}$ in the highest burnup capsule assembly (Cowell 1997a).

Step K Transfer the test assembly to the ATR Canal

The test assembly will be removed from the I-24 core position, inserted into a transfer bucket and then transferred to the canal per DOP 7.2.17.

Step L Disassemble the test assembly on the working tray in the canal

The test assembly will be disassembled in the canal using tools specifically designed for the disassembly/re-assembly. All nine capsule assemblies will be removed and placed in a specifically designed MOX capsule carrier.

Step M Transfer two unirradiated capsule assemblies from the TRA Plug Storage Area North to the ATR Canal

Two unirradiated MOX fuel capsule assemblies (\#6 and \#12) will be transported from the TRA Plug Storage Area North to the ATR Canal in an approved intra-TRA transport container -- DOT-authorized Type B fissile material transport package consisting of a 10 gallon DOT Specification 6M drum, with DOT Specification 2R inner containment vessel. Transport will be in compliance with RPSP 10.6.4.6, "TRA Unirradiated Fissile Material Control."

The two MOX fuel capsule assemblies contain a total of approximately $7.2 \mathrm{~g}$ of accountable plutonium (Pu-239/241), approximately $0.4 \mathrm{~g}$ accountable Uranium (U$235)$, and approximately $0.4 \mathrm{~g}$ of non-accountable plutonium $(\mathrm{Pu}-240)$. 
MOX FUEL IRRADIATION ESAP

DAR No.: MOX-ESAP-3 May 2000

Step $\mathrm{N} \quad$ Assemble the test assembly on the working tray in the canal

Nine capsule assemblies, seven irradiated and two unirradiated (\#6 and \#12), will be loaded in the basket assembly Model-2, per the loading pattern shown in Figure 6, on the working tray in the canal per Canal O\&MM and Canal Loading Record. (Insert the new flux wires as necessary per Step G.) The basket assembly Model-1 will be stored in the canal and will be shipped to ORNL with the Model-2 assembly at a later date, if required.

Step O Insert the experiment assembly in the reactor

The experiment assembly will be loaded in the reactor I-24 hole location per DOP 7.2.17.

Step P Store and load two irradiated capsule assemblies in the canal.

Two irradiated capsule assemblies (\#1 and \#8) will be stored in the specifically designed and approved MOX capsule carrier in the canal storage area in accordance with existing ATR Canal Storage methodology and procedures. These capsule assemblies will be loaded, at least thirty days after the end of cycle (EOC) as schedule permits, in the Hot Cell Carrier (HCC) \#3 cask at the ATR canal per DOPs 4.8.7, and 4.8.46.

Step PA Transport two irradiated capsule assemblies to the TRA Hot Cell Facility.

Two irradiated capsule assemblies (\#1 and \#8) will be transported to the TRA HCF per DOP 4.8.19

Step PB Package two irradiated capsule assemblies and transport to ORNL.

Two irradiated capsule assemblies (\#1 and \#8) will be transferred from the HCC \#3 cask into the GE-100 cask at the TRA HCF in accordance with HCF procedures that reflect the facilities operating requirements and cask Certificate of Compliance requirements. The loaded cask will be transported to ORNL per applicable DOT and NRC requirements.

Step Q Irradiate the test assembly

The test assembly will be irradiated in the reactor. The test assembly will remain in the reactor position until the highest-burnup capsule assembly has reached desired burnup of $\sim 20 \mathrm{GWd} / \mathrm{MT}$. Preliminary depletion calculations indicate that $\sim 14$ calendar months of irradiation in Phase II will be required to achieve an average burnup of $20 \mathrm{GWd} / \mathrm{MT}$ in the highest burnup capsule assembly (Cowell 1997a). (Repeat the steps E through H as necessary for flux wire changeout.)

Step R Transfer the test assembly to the ATR Canal

The test assembly will be removed from the reactor and transferred to the canal per DOP 7.2.17. 
MOX FUEL IRRADIATION ESAP

DAR No.: MOX-ESAP-3 May 2000

Step S Disassemble the test assembly on the working tray in the canal

The test assembly will be disassembled on the working tray in the canal using tools specifically designed for the disassembly/re-assembly. All nine capsule assemblies will be removed and placed in a specifically designed MOX capsule carrier.

Step T Receive two dummy capsule assemblies in the canal area

Two dummy assemblies will be received in the canal area. The dummy assemblies will be transported by routine methods since they are not large, heavy, radioactive, or hazardous.

Step $U$ Assemble the test assembly on the working tray in the canal

Nine capsule assemblies, seven irradiated and two dummy capsule assemblies, will be loaded in the basket assembly, per the loading pattern shown in Figure 7, on the working tray in the canal per Canal O\&MM and Canal Loading Record.

Step V Insert the reconfigured experiment assembly in the reactor

The experiment assembly will be loaded in the reactor location I-24 hole per DOP 7.2.17.

Step W Irradiate the test assembly

The test assembly will be irradiated in the reactor. The test assembly will remain in the reactor position until the lead capsule assembly has reached desired burnup of 30 GWd/MT. Preliminary depletion calculations indicate that 12 calendar months of irradiation in Phase III will be required to achieve an average burnup of $30 \mathrm{GWd} / \mathrm{MT}$ in the highest burnup assembly (Cowell 1997a). (Repeat steps E through H as necessary for flux wire changeout.)

Step X Store and load two irradiated capsule assemblies in the canal.

Two irradiated capsule assemblies (\#2 and \#9) will be stored in the specifically designed and approved MOX capsule carrier in the canal storage area in accordance with existing ATR Canal Storage methodology and procedures. The capsule assemblies will be loaded, at least thirty days after EOC as schedule permits, into the GE-100 cask at the ATR Canal in accordance with ATR Canal procedures that reflect the facilities operating requirements and cask Certificate of Compliance requirements.

Step XA Transport two irradiated capsule assemblies to ORNL.

Two irradiated capsule assemblies in GE-100 cask will be transported to ORNL per applicable DOE, DOT, and NRC requirements. 
MOX FUEL IRRADIATION ESAP

DAR No.: MOX-ESAP-3 May 2000

Step Y Transfer the test assembly to the ATR Canal

The test assembly will be removed from the reactor and transferred to the canal per DOP 7.2.17.

Step Z Disassemble the test assembly on the working tray in the canal

The test assembly will be disassembled on the working tray in the canal per O\&MM 7.10.13.1.3, section 4.2, capsule and Experiment Handling and the Canal Loading Record.

Step YA Store four irradiated capsule assemblies in the canal and later load two capsule assemblies into GE-100 cask.

Four irradiated capsule assemblies (\#3, 4, 10 and 13) will be stored in the specifically designed and approved MOX capsule carrier in the canal storage area in accordance with existing ATR Canal Storage methodology and procedures. Two capsule assemblies (\#3 and 10) will be loaded, at least thirty days after EOC as schedule permits, into the GE-100 cask at the ATR Canal in accordance with ATR Canal procedures that reflect the facility's operating requirements and cask Certificate of Compliance requirements.

OR

The capsule assemblies will be loaded at least thirty days after EOC as schedule permits, in the HCC \#3 cask at the ATR canal per DOPs 4.8.7, and 4.8.46 to transport to HCF. The irradiated capsule assemblies will be transported to the TRA HCF per DOP 4.8.19.

Step YB Transport two irradiated capsule assemblies to ORNL.

Two irradiated capsule assemblies in a GE-100 cask will be transported to ORNL per applicable DOE, DOT, and NRC requirements.

Step YC Receive four unirradiated dummy capsule assemblies in the canal area

Four dummy capsule assemblies will be received in the canal area. The dummy assemblies will be transported by routine methods since they are not large, heavy, radioactive, or hazardous.

Step YD Assemble the test assembly on the working tray in the canal

Nine capsule assemblies, three irradiated (\#5, 6, and 12) and six dummy capsule assemblies, will be loaded in the basket assembly, per the loading pattern shown in Figure 7a, on the working tray in the canal per O\&MM 7.10.13.1.3, section 4.2, capsule and Experiment Handling and the Canal Loading Record. 
Step YE Insert the reconfigured experiment assembly in the reactor

The experiment assembly will be loaded in the reactor location I-24 hole per DOP 7.2.17.

Step YF Irradiate the test assembly

The test assembly will be irradiated in the reactor. The test assembly will remain in the reactor position until the lead capsule assembly has reached desired burnup of approximately $30 \mathrm{GWd} / \mathrm{MT}$. Preliminary depletion calculations indicate that six calendar months of irradiation in Phase III, Part 2 will be required to achieve an average burnup of $30 \mathrm{GWd} / \mathrm{MT}$ in the highest burnup assembly (Chang 2000). (Repeat steps E through H as necessary for flux wire change out.)

Step YG Transfer the test assembly to the ATR Canal

The test assembly will be removed from the reactor and transferred to the canal per DOP 7.2.17.

Step YH Disassemble the test assembly on the working tray in the canal

The test assembly will be disassembled on the working tray in the canal per O\&MM 7.10.13.1.3, section 4.2, capsule and Experiment Handling and the Canal Loading Record. Three capsule assemblies and six dummy assemblies will be removed and placed in the specifically designed and approved MOX capsule carrier in the canal storage area.

The following steps will be executed only if it is decided not to extend the burnup of MOX capsule assemblies; otherwise a new ESAP will be issued.

Step AA Store the capsule assemblies and dummy assemblies in the canal

Five capsule assemblies and six dummy capsule assemblies will be stored in the specifically designed and approved MOX capsule carrier in the canal storage area in accordance with existing ATR Canal Storage methodology and procedures. The empty basket assembly will also be stored in the canal storage area. The capsule assemblies will be stored at least thirty days after EOC before shipping to the ORNL or the HCF.

Step AB Load the irradiated capsule assemblies and basket assemblies in the canal for shipment to the ORNL. 
MOX FUEL IRRADIATION ESAP

DAR No.: MOX-ESAP-3 May 2000

The capsule assemblies will be loaded, at least thirty days after EOC as schedule permits, into the GE-100 cask at the ATR Canal in accordance with ATR Canal procedures that reflect the facilities operating requirements and cask Certificate of Compliance requirements. The loaded cask will be transported to ORNL per applicable DOT and NRC requirements.

If desired, the empty basket assemblies will be loaded into the GE-2000 cask per DOP 4.8.4 and shipped to the ORNL via commercial carrier. The loaded cask will be transported to ORNL per applicable DOE, DOT, and NRC requirements.

Step ZA Load the irradiated capsule assemblies in the canal to ship to the HCF.

The capsule assemblies (\#3 and 10) will be loaded, at least thirty days after EOC as schedule permits, in the HCC \#3 cask at the ATR canal per DOPs 4.8.7, and 4.8.46 to transport to $\mathrm{HCF}$.

If desired, the empty basket will be loaded into the GE-2000 cask per DOP 4.8.4 and shipped to the ORNL via commercial carrier. The loaded cask will be transported to ORNL per applicable DOE, DOT, and NRC requirements.

Step ZB Transport the irradiated capsule assemblies to the TRA HCF.

The irradiated capsule assemblies will be transported to the TRA HCF per DOP 4.8.19.

Step ZC Package the irradiated capsule assemblies and transport to ORNL.

The irradiated capsule assemblies will be loaded into the GE-100 cask at the TRA HCF in accordance with HCF procedure that reflect the facilities operating requirements and cask Certificates of Compliance requirement. The loaded cask will be transported to ORNL per applicable DOT and NRC requirements.

The waste generated during operation associated with this experiment is the generation of routine solid contaminated waste such as Anti-Cs, blotter paper, etc. and liquid waste from the cask vacuum drying process (canal water). These wastes are disposed with other contaminated waste generated during operation of the ATR. All wastes are required to have a hazardous waste determination to show if the wastes are regulated under the Resources Conservation and Recovery Act or other applicable federal regulations. This determination is performed by the generator and is then approved for inclusion in waste streams for recycling and disposal of solid wastes. Any new wastes that are generated from the irradiation or Hot Cell processing activities must have an approved hazardous waste determination prior to disposal of the waste to ensure the waste is placed in the appropriate waste streams.

It is a written Commitment of this project made by Dr. S. A. Hodge, Manager, MOX Irradiation Test Project of ORNL, that all of the irradiated capsules and other hardware items associated with this test (except the flux wires) will be transported to ORNL, where post-irradiation 
MOX FUEL IRRADIATION ESAP

DAR No.: MOX-ESAP-3 May 2000

examination (PIE) will be performed as appropriate (Hodge 1997b). ORNL will prepare a formal plan to describe the shipments of the irradiated capsules. INEEL has the option to dispose of the empty baskets and related hardware in Idaho if that is more cost effective than shipping the material to ORNL.

There are no special requirements for facility set points or alarms in any of the above steps. The standard requirements for reactor tank and material handling are sufficient.

\subsection{Safety Envelopes}

\section{Steps E, J, Q, W, and YF Irradiation of fuel in the ATR}

\section{Steps F, G, H, K, L, N, O, P, R , S, U, V, X, Y, Z, ZA, AA, AB, YA, YD, YE, YG, YH, YJ} Canal activities

The safety envelope for irradiation of the experiments in the ATR and ATR canal activities is defined by the ATR Technical Safety Requirements (TSR) (ATR 1998), ATR UFSAR (ATR 1999), and analyses listed below.

\begin{tabular}{|l|l|}
\hline \multicolumn{1}{|c|}{ Analysis } & \multicolumn{1}{|c|}{ References } \\
\hline Thermal & $\begin{array}{l}\text { Ott 1997, 1998a,1998b } \\
\text { Ambrosek 1997a, 1997b, } \\
\text { 1998a, 1998b, 2000 } \\
\text { Hodge 1997b, 1997c }\end{array}$ \\
\hline Stress & $\begin{array}{l}\text { Corum 1997, 1998 } \\
\text { Morton 1997 } \\
\end{array}$ \\
& Thoms 1997a, 1997b \\
\hline
\end{tabular}

ORNL performed experiments to validate the use of the FFFAP code for analyzing the thermalhydraulics of the MOX irradiation tests (Ott 1998b). The test flow rates and pressure gradient data are found to be in good agreement with calculated data and are acceptable (Ambrosek 1998a, 1998b).

The Model-2 basket was checked for vibration damage during flow testing of the Model-2 MOX test basket assembly (Ott 1998b). There were no observable changes in sound or feel (vibration) in the basket assembly (differential pressures ranging from 10 to 90 psid) such as would have indicated excessive vibration. Magnetometer readings (a cell placed on outside of assembly at axial location approximately at centerline of top dummy capsule) were acquired at each data collection point (10 psid increments); this data also indicates no excessive vibration. The Model2 basket assembly design documents has been reviewed and approved by the design review committee (Grover 1998a). 
MOX FUEL IRRADIATION ESAP

DAR No.: MOX-ESAP-3 May 2000

\section{Steps M, PA, XA, ZB, T, and YC Transport of unirradiated or irradiated capsule assemblies within TRA}

The safety envelope for the MOX fuel capsule assemblies (unirradiated and irradiated) transport within the TRA is established by the applicable Operating Procedures as discussed in Section 4.2 , along with the DOT regulations for the $6 \mathrm{M}$ drum and the controls associated with the Certificates of Compliance for the GE-100 cask and GE-2000 cask.

Gentillo (1992) contains an engineering evaluation of the HCC \#3 cask. The internal heatup of MOX capsule assemblies has been analyzed by Hawkes $(1998,1999 a, 1999 b)$ and found to be acceptable relative to heat generation limits noted in Sherick (1992).

\section{Steps PB, X, ZA, ZC, AB, and YB Shipping activity (Cask Handling and HCF)}

The safety envelope for cask handling within the ATR is established by the ATR TSR 3.5.5, Cask Handling and Irradiated Fuel Storage (ATR 1998), the ATR UFSAR (ATR 1999), and cask Certificates of Compliance. The loaded GE-100 and GE-2000 casks will be transported to ORNL per applicable DOE, DOT and NRC requirements.

The safety envelope for the TRA HCF is defined by the TRA Hot Cell Safety Analysis Report (SAR) and Technical Safety requirements (TSR).

The GE-100 cask at the TRA HCF will be loaded in accordance with HCF procedures that reflect the facilities operating requirements and cask Certificate of Compliance requirements. The loaded cask will be transported to ORNL per applicable DOE, DOT and NRC requirements.

The internal heatup of MOX capsule assemblies \# 3 and 10 in the shipping cask will be analyzed prior to shipment when the decay heat rates become available and confirmed to meet shipping cask requirements prior to shipment. It is expected that the results will be bounded by the previous analysis, Hawkes (1998, 1999a, 1999b). 
MOX FUEL IRRADIATION ESAP

DAR No.: MOX-ESAP-3 May 2000

\section{DEMONSTRATION OF COMPLIANCE}

This section shows compliance with the ATR TSR/UFSAR requirements that are to be met.
Table 2 shows compliance with the safety envelope.

Table 2. Demonstration of Compliance

ALL EXPERIMENTS

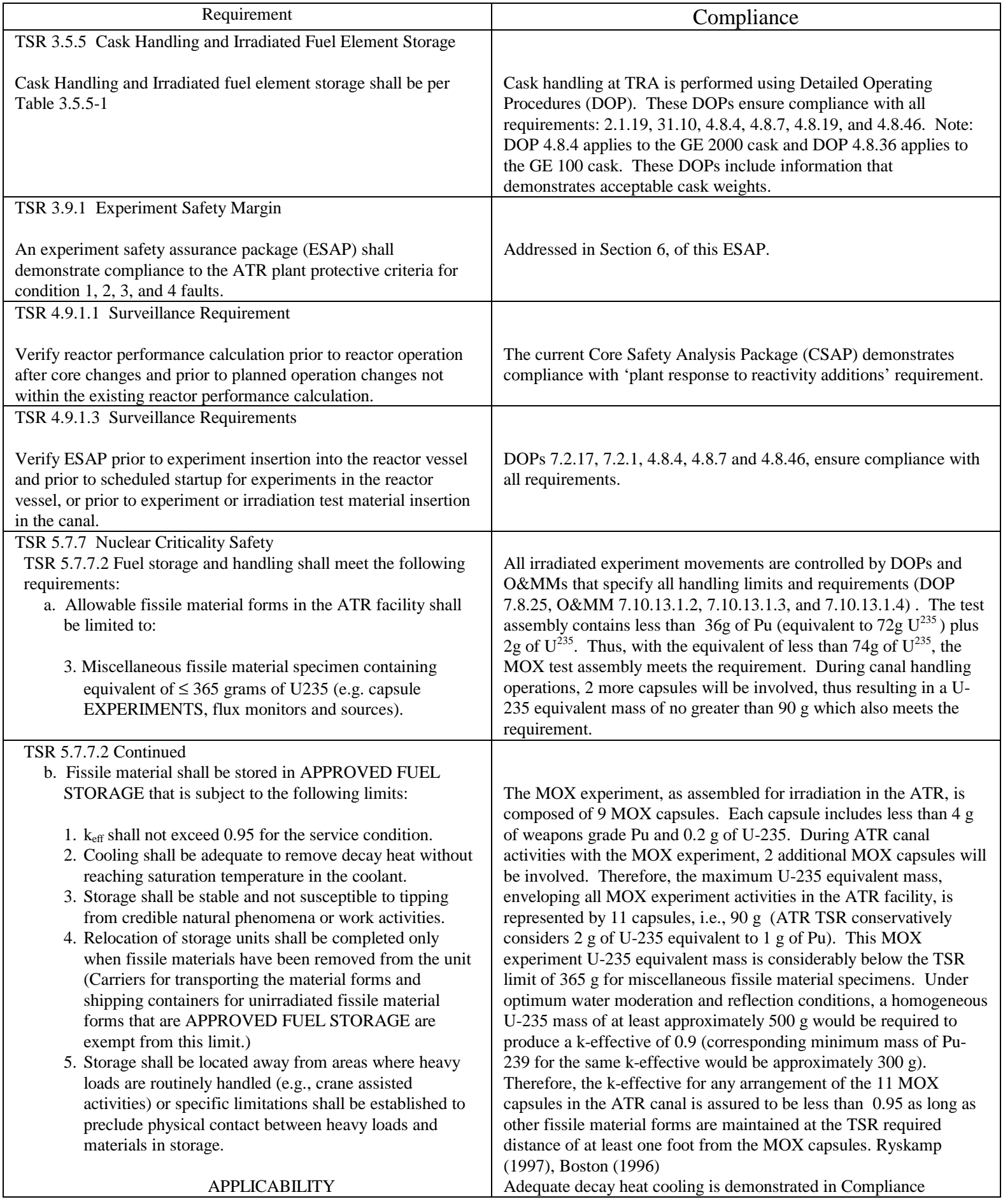


MOX FUEL IRRADIATION ESAP

DAR No.: MOX-ESAP-3 May 2000

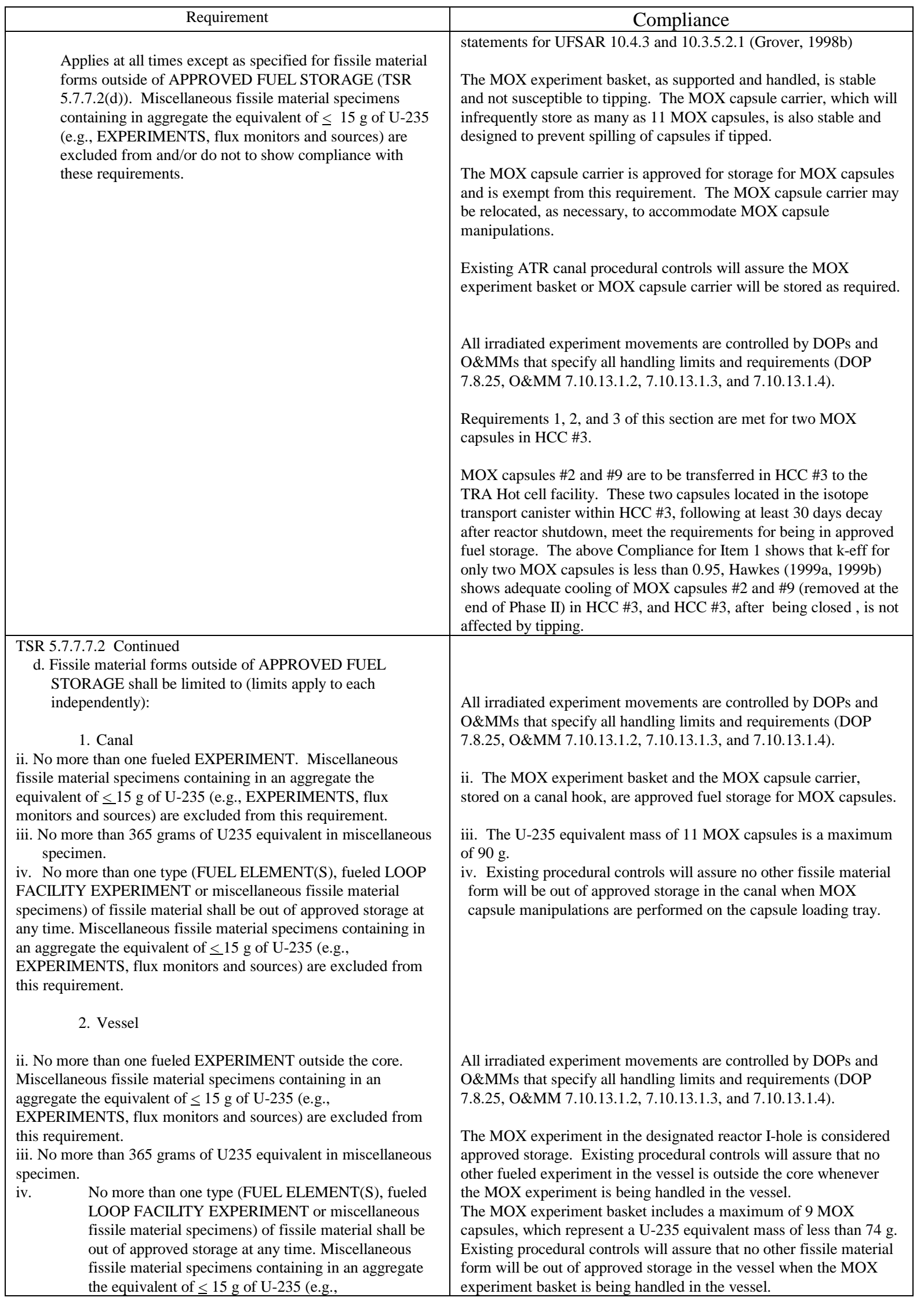


MOX FUEL IRRADIATION ESAP

DAR No.: MOX-ESAP-3 May 2000

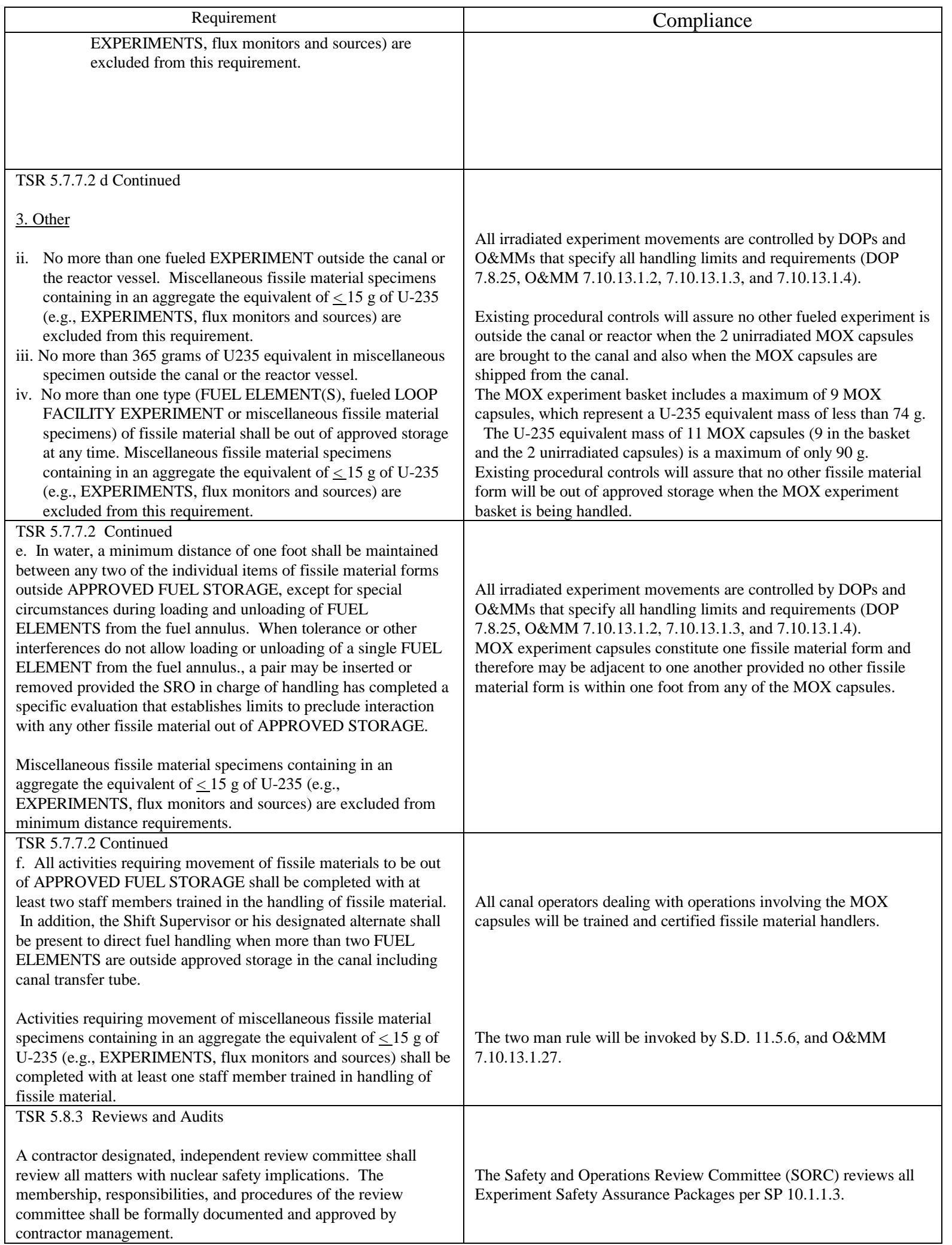


MOX FUEL IRRADIATION ESAP

DAR No.: MOX-ESAP-3 May 2000

\begin{tabular}{|c|c|}
\hline \multirow{2}{*}{$\begin{array}{r}\text { Requirement } \\
\text { UFSAR 4.3.2.2 Power Distribution }\end{array}$} & Compliance \\
\hline & \\
\hline $\begin{array}{l}\text { Due to nature of ATR operation new experiments are occasionally } \\
\text { inserted into the reactor. When new experiments are placed into } \\
\text { the reactor, additional analysis is performed to provide assurance } \\
\text { that the reactor response with new experiments meets the } \\
\text { established safety envelope. }\end{array}$ & $\begin{array}{l}\text { MOX experiment does not require any additional analysis since the } \\
\text { experiment is irradiated in the I- } 24 \text { position. Experiments located in } \\
\text { the I- } 24 \text { position have no significant effect on the ATR axial flux } \\
\text { profile in the reactor fuel }\end{array}$ \\
\hline \multicolumn{2}{|l|}{ UFSAR 10.1.7.1 Primary Experiment Safety Analyses Criterion } \\
\hline $\begin{array}{l}\text { The consequences of normal operation of the experiment and of } \\
\text { any experiment fault must be bounded by the ATR Plant } \\
\text { Protection Criteria for the same operating condition (i.e., } \\
\text { Condition 1,2,3, and } 4 \text { as defined in Chapter } 15 \text { (Accident } \\
\text { Analyses)). } \\
\text { The primary experiment safety analyses criterion applies } \\
\text { whenever the experiment is within the ATR facility. }\end{array}$ & $\begin{array}{l}\text { Compliance to this requirement is demonstrated in Section } 6 \text { and } 7 \text { of } \\
\text { this ESAP. Faw (1998) concluded, based on ORIGEN } 2 \text { and RSAC- } \\
5 \text { calculations, that the MOX fuel would contribute less than } 0.1 \% \text { of } \\
\text { the total dose at the LPZ (low population zone) if a postulated large } \\
\text { break resulted in a release of radionuclides from both the ATR fuel } \\
\text { and the MOX fuel. Based on a postulated confinement leak rate of } \\
\text { 100\% day, Faw calculated LPZ doses from MOX fuel of only } 0.210 \\
\text { rem thyroid and } 0.0132 \text { rem EDE. See Terry (1998b) for the } \\
\text { clarification of table headings in Faw (1998) reference. }\end{array}$ \\
\hline \multicolumn{2}{|l|}{$\begin{array}{l}\text { UFSAR 10.1.7.2 General Experiment Safety Analyses Criterion } \\
\text { for Experiments Containing Fissile Material }\end{array}$} \\
\hline $\begin{array}{l}\text { The following general experiment safety analyses criterion must } \\
\text { be met for any experiment containing fissile material: } \\
\text { The experiment fissile material form and content must be } \\
\text { shown to be enveloped by the existing criticality safety } \\
\text { evaluations described in Chapter } 9 \text { (Auxiliary Systems) and } \\
\text { the TSR administrative controls for nuclear criticality safety. } \\
\text { This general experiment safety analyses criterion for experiments } \\
\text { containing fissile material applies whenever the experiment is } \\
\text { within the ATR facility. If this criterion is not met, additional } \\
\text { criticality safety evaluations and appropriate changes to the TSR } \\
\text { administrative controls must be made prior to conducting the } \\
\text { experiment. }\end{array}$ & $\begin{array}{l}\text { At most, there will be eleven MOX capsules in the canal at any one } \\
\text { time. This would represent less than } 90 \mathrm{~g} \text { of U- } 235 \text { equivalent. Per } \\
\text { UFSAR 9.1.2.1, "Fissile material units, except ATR elements and } \\
\text { loop experiments, are limited to } \leq 365 \mathrm{~g} \text { U- } 235 \text { equivalent (plus } \geq 1 \\
\text { foot spacing) so that k-effective need not be considered." } \\
\text { Experiment manipulations involving the MOX capsules are } \\
\text { addressed by existing procedural controls which will assure the } \\
\text { criticality safety evaluations of Chapter } 9 \text { are enveloping. } \\
\text { Administrative controls for nuclear criticality safety are addressed } \\
\text { under TSR 5.7.7, contained in this section. }\end{array}$ \\
\hline \multicolumn{2}{|l|}{ UFSAR 10.1.7.3.2 Code Compliance of Experiment Containment } \\
\hline $\begin{array}{l}\text { Experiment containment that holds pressure greater than } 235 \text { psig, } \\
\text { or contains material that can generate pressure pulses greater than } \\
430 \text { psig, must have a design that meets the intent of ASME } \\
\text { Section III, Class } 1 \text { standards, or the ability, demonstrated by } \\
\text { prototype testing or other means, to withstand service conditions } \\
\text { without failure. }\end{array}$ & $\begin{array}{l}\text { Each capsule assembly has been designed as a Class } 1 \text { vessel and } \\
\text { satisfies the appropriate rules specified in subsection NB, Section III, } \\
\text { Division } 1 \text { of the ASME B\&PV Code. Based on the best estimate } \\
\text { analysis, Hodge } 1997 \mathrm{~b} \text {, MOX fuel pin gas plenum pressure is } \\
\text { calculated to be } 131 \text { psia (for } 30,000 \mathrm{MWd} / \mathrm{MT} \text { ), which is less than } \\
235 \text { psig. }\end{array}$ \\
\hline \multicolumn{2}{|l|}{ UFSAR 10.1.7.3.3 Containment of Materials } \\
\hline $\begin{array}{l}\text { Materials which are incompatible with the reactor fuel element } \\
\text { cladding, the reactor primary coolant, canal water coolant, or with } \\
\text { reactor primary coolant system (PCS) structural materials must be } \\
\text { contained to ensure they are not released to the PCS or canal as a } \\
\text { result of a Condition } 2 \text { or } 3 \text { fault. } \\
\text { Incompatible materials, normally used as activation monitors, } \\
\text { must be secured to minimize the likelihood of being lost in the } \\
\text { reactor PCS. }\end{array}$ & $\begin{array}{l}\text { All the materials associated with the MOX experiment assembly are } \\
\text { compatible with the primary coolant and/or with the PCS structural } \\
\text { materials. Gallium (about } 2 \mathrm{ppm} \text { ) in the fuel pellets, is inside } \mathrm{Zr} \text { - } \\
\text { clad, which in turn is encapsulated in a stainless steel pressure vessel } \\
\text { that meets ASME Section III code requirements. Gallium will not } \\
\text { migrate to the stainless steel capsule. } \\
\text { Standard ATR flux monitor wires will be contained in an aluminum } \\
\text { holder tube and secured in the basket assembly. }\end{array}$ \\
\hline \multicolumn{2}{|l|}{ UFSAR 10.1.7.3.4 Excluded Materials } \\
\hline $\begin{array}{l}\text { The following materials are not permitted in an experiment or } \\
\text { loop facility within the reactor biological shielding. } \\
\text { Unknown Materials - No experiments shall be performed unless } \\
\text { the material content, with the exception of trace constituents, is } \\
\text { known. }\end{array}$ & $\begin{array}{l}\text { Materials contained in this experiment are identified via Wachs } 1997 \\
\text { (listing of Drawings is provided in the Reference) of this ESAP. } \\
\text { Chidester } 1998 \text { presents the uranium and plutonium loadings. } \\
\text { Gallium (about } 2 \text { ppm) is present in the fuel pellets, which is inside } \\
\text { Zr-clad, which in turn is encapsulated in a stainless steel pressure } \\
\text { vessel that meets ASME Section III code requirements. }\end{array}$ \\
\hline $\begin{array}{l}\text { Explosive materials with an equivalent of } \geq 25 \mathrm{mg} \text { of TNT. } \\
\text { (Explosive material is a solid or liquid which has an explosion } \\
\text { hazard in water or steam, as defined in Lewis (1990), and is used }\end{array}$ & This experiment contains no explosive materials. \\
\hline
\end{tabular}


MOX FUEL IRRADIATION ESAP

DAR No.: MOX-ESAP-3 May 2000

\begin{tabular}{|c|c|}
\hline Requirement & Compliance \\
\hline $\begin{array}{l}\text { in a configuration that can detonate and produce a shock wave.) } \\
\text { Cryogenic liquids }\end{array}$ & This experiment contains no cryogenic materials. \\
\hline UFSAR 10.1.7.3.5 Evaluation of Materials & \\
\hline $\begin{array}{l}\text { The following materials are not used in experiments unless such } \\
\text { usage is shown to be in compliance with the primary experiment } \\
\text { safety analyses criterion in section } 10.1 .7 \text {, and the compliance } \\
\text { analyses are completed prior to insertion in the reactor vessel or } \\
\text { canal. } \\
\text { Radiologically hazardous activation products. } \\
\text { Radiation sensitive materials. } \\
\text { Highly flammable or toxic materials, per se or as by-products of } \\
\text { radiation sensitive materials. } \\
\text { Reactive Materials which are defined as any solid or liquid which } \\
\text { has a reactivity index of } 2 \text { in National Fire Protection Association } \\
\text { Publication } 704 \text { (NFPA 1996) or has a disaster or fire hazard } \\
\text { indicating detrimental reactions in water or steam (Lewis 1990). }\end{array}$ & $\begin{array}{l}\text { The containment, irradiation monitoring, shielding and operational } \\
\text { controls are adequate for the material content of this experiment. } \\
\text { Section } 7 \text { of this ESAP provides the detailed Safety Analysis for } \\
\text { Radiation exposure and Barrier Protection. } \\
\text { The experiment contains uranium and weapons grade plutonium. } \\
\text { Peak total activity from the actinides + daughter and other fission } \\
\text { products (MOX fuel) is calculated to be considerably less than the } \\
\text { total activity from the actinides + daughter and other fission products } \\
\text { (ATR fuel) generated during normal ATR fuel cycles (Hodge } \\
\text { 1997c). } \\
\text { Wilson (1997) states that intermetallic compound formation is the } \\
\text { principal interaction mechanism between zircaloy and gallium. This } \\
\text { interaction is very limited by the low mass of gallium (about } 2 \text { ppm), } \\
\text { so problems are not expected with the zircaloy cladding. The } \\
\text { stainless steel will not interact with gallium because no gallium will } \\
\text { migrate through the zircaloy. }\end{array}$ \\
\hline $\begin{array}{l}\text { UFSAR 10.1.7.3.7 Physical Layout } \\
\text { Components of experiment facilities are located and oriented to } \\
\text { preclude physical interference with personnel evacuation or with } \\
\text { safety-related systems, structures, and components. If } \\
\text { displacement of system shielding is involved, measures are to be } \\
\text { taken to ensure radiation levels are below the ATR Plant } \\
\text { Protection Criteria for occupational exposure. }\end{array}$ & $\begin{array}{l}\text { The test assembly is inserted in position I-24, thus precluding } \\
\text { physical interference with reactor components. No displacement of } \\
\text { reactor shielding is involved. }\end{array}$ \\
\hline $\begin{array}{l}\text { UFSAR 10.1.7.4 Thermal Hydraulic Criteria } \\
\text { The conduct of the experiment must not adversely affect decay } \\
\text { heat transfer from the canal fuel elements or heat transfer from the } \\
\text { PCS. }\end{array}$ & $\begin{array}{l}\text { While in the core this experiment is in an existing irradiation facility } \\
\text { away from the fuel elements. While in the canal it will be located on } \\
\text { a canal hook, on the capsule loading tray or in a specially fabricated } \\
\text { carrier, away from the fuel storage grids. The conduct of the } \\
\text { experiment will not adversely affect decay heat transfer from the } \\
\text { canal fuel elements or heat transfer from the PCS. }\end{array}$ \\
\hline $\begin{array}{l}\text { UFSAR 10.1.8.1 Quality Review } \\
\text { The design, fabrication, testing, and material content of all } \\
\text { contractor-supplied experiment hardware are verified in } \\
\text { accordance with the contractor's Quality Program Plan (See } \\
\text { Chapter 17, Quality Assurance). For experiment hardware } \\
\text { supplied by other organizations, the design, fabrication, testing } \\
\text { and material content are verified in accordance with a Quality } \\
\text { Program that has been reviewed by the contractor and found to } \\
\text { meet the intent of the applicable sections of the contractor Quality } \\
\text { Program Plan or the contractor verifies that the experiment meets } \\
\text { the intent of the applicable sections of the contractor Quality } \\
\text { Program Plan. These quality reviews are documented in the ESA. }\end{array}$ & $\begin{array}{l}\text { The design, fabrication, testing, and verification of material content } \\
\text { was performed by ORNL and LANL. The documentation associated } \\
\text { with these activities has been reviewed for compliance with } \\
\text { requirements by INEEL, Ambrosek (1997a, 1998a, and 1998b) } \\
\text { Morton 1997, West (1997a, 1997b). } \\
\text { The fabrication, testing, and material content of the ORNL and } \\
\text { LANL supplied components have been reviewed by Quality (Cooper } \\
\text { 1998) and found to be acceptable. For Model-2 basket assembly see } \\
\text { nonconformance report (NCR 1998), and Hodge (1998a) }\end{array}$ \\
\hline $\begin{array}{l}\text { UFSAR 10.1.8.2 Supporting Analyses } \\
\text { The contractor is responsible for the adequacy and accuracy of } \\
\text { supporting analyses submitted by the experimenter organizations. } \\
\text { The operation of each experiment facility is compared to the } \\
\text { facility design specification to assure that it is properly enveloped. } \\
\text { Each experiment is compared to the safety analysis envelope to } \\
\text { assure consistency with the assumptions made in the analyses. }\end{array}$ & $\begin{array}{l}\text { The analyses in support of this experiment were performed by } \\
\text { ORNL, Corum, (1997, 1998), Ott (1997, 1998a, 1998b), Hodge } \\
\text { (1997b, 1997c), Thoms (1997a, 1997b) and LANL, Chidester } \\
\text { (1998). } \\
\text { INEEL, Ambrosek (1997a, 1998a, 1998b), Morton (1997), West } \\
\text { (1997a, 1997b) reviewed the analyses for adequacy and accuracy } \\
\text { (including assumptions to the supporting analyses). Other INEEL } \\
\text { assessments, e.g. Tomberlin (1997) have been performed. }\end{array}$ \\
\hline $\begin{array}{l}\text { UFSAR 10.1.8.3 Independent Safety Review } \\
\text { Each ESAP has an independent safety review. }\end{array}$ & This ESAP has been presented to and approved by SORC. \\
\hline
\end{tabular}


MOX FUEL IRRADIATION ESAP

DAR No.: MOX-ESAP-3 May 2000

\begin{tabular}{|c|c|}
\hline Requirement & Compliance \\
\hline $\begin{array}{l}\text { A Contractor-designated, multi-disciplined independent safety } \\
\text { review committee reviews each experiment and the analyses that } \\
\text { is used to verify compliance to this UFSAR and the TSR, and } \\
\text { presents recommendations to the Reactor Programs Director. } \\
\text { The independent safety review committee concurs with } \\
\text { conducting the experiment. }\end{array}$ & \\
\hline $\begin{array}{l}\text { UFSAR 10.4.3 Experiment Handling Evaluations } \\
\text { For fueled experiments, a minimum cooling time after shutdown } \\
\text { will be established to assure that melting of the experiment will } \\
\text { not occur during handling of the experiment. For loop } \\
\text { experiments, a minimum cooling time after shutdown of eight } \\
\text { hours has been established (Hendrickson 1997a). If necessary, a } \\
\text { short time may be supported by the ESA. }\end{array}$ & $\begin{array}{l}\text { Ambrosek 1997b states that a horizontal MOX capsule on the canal } \\
\text { floor four hours after ATR shutdown will not boil on the capsule } \\
\text { surface, which precludes any potential for dryout and a temperature } \\
\text { excursion. The MOX assembly has no reverse flow device to hinder } \\
\text { natural convection. Natural convection cooling in the MOX } \\
\text { assembly is expected to be better than in an ATR fuel element } \\
\text { because a large portion of the operational pressure drop is across an } \\
\text { orifice. Therefore, MOX fuel melting will not occur in the canal. } \\
\text { Restrictions will be placed in the Reactor Loading Record to prohibit } \\
\text { transfer of the test assembly out of the reactor and to the canal in less } \\
\text { than four (4) hours after a reactor scram. }\end{array}$ \\
\hline $\begin{array}{l}\text { UFSAR 10.4.3 Experiment Handling Evaluations (continued) } \\
\text { The ESA addresses a) handling operations which can include } \\
\text { assembly, disassembly, storage, and cask handling, b) limiting } \\
\text { fault analyses for each handling evolution, and c) effects on the } \\
\text { experiment during a canal draining accident and demonstrates } \\
\text { compliance with the ATR Plant Protection Criteria for all } \\
\text { applicable operating conditions. }\end{array}$ & $\begin{array}{l}\text { The demonstration of compliance with the ATR Plant Protection } \\
\text { Criteria for all applicable operating conditions is addressed in } \\
\text { Section 7, Plant Protection Criteria, of this document. } \\
\text { c) Thermal calculations for an irradiated MOX capsule cooled by } \\
\text { natural convection of ambient air (as would be encountered in a } \\
\text { drained canal) show that a canal draining event beginning four (4) } \\
\text { hours after reactor scram would result in no melting of any fuel or } \\
\text { structural material in the test assembly (Bayless, 1998). }\end{array}$ \\
\hline $\begin{array}{l}\text { UFSAR 10.4.3 Experiment Handling Evaluations (continued) } \\
\text { Various experiment handling evolutions require the use of } \\
\text { building cranes. Formal documentation shall be available to show } \\
\text { limits for each crane used. The document shall indicate load } \\
\text { limits, lift heights, allowable reactor status (e.g., operating, } \\
\text { shutdown, or defueled) and allowable status of canal storage. } \\
\text { Verification of the required documentation is an element of the } \\
\text { ESA. }\end{array}$ & $\begin{array}{l}\text { DOP 4.8.4, which applies to the GE } 2000 \text { Cask, DOP } 4.8 .36 \text { which } \\
\text { applies to the GE 1OOCask, or DOP } 4.8 .7 \text { which applies to the HCC } \\
\# 3 \text { Cask, shall be used when experiment handling requires its use for } \\
\text { the MOX experiment. These casks have been approved for ATR } \\
\text { and the corresponding DOP references the requirements of this } \\
\text { section of the UFSAR. }\end{array}$ \\
\hline CAPSULE EXPERIMENT ONLY & \\
\hline $\begin{array}{l}\text { UFSAR 10.1.5 Classification of Experiment Structures, Systems, } \\
\text { and Components (SSC) }\end{array}$ & \\
\hline $\begin{array}{l}\text { Classification of the capsule and canal experiment SSC and the } \\
\text { applicability of General Design Criterion } 70 \text { to capsule } \\
\text { experiment SSC are addressed on a case basis in the ESA for the } \\
\text { capsule. }\end{array}$ & $\begin{array}{l}\text { There are no important-to-safety SSC for this capsule experiment } \\
\text { that need to meet General Design Criterion } 70 \text {. Experiment fault } \\
\text { consequences are consistent with those of the reactor and its } \\
\text { associated systems. }\end{array}$ \\
\hline $\begin{array}{l}\text { UFSAR 10.3.5.1.1 Comparison to Safety Analyses (Reactivity } \\
\text { Insertion Rate) } \\
\text { The potential reactivity insertion rate shall not exceed the } \\
\text { reactivity insertion rate of the limiting event in each fault category } \\
\text { analyzed in the UFSAR without additional analyses to show } \\
\text { acceptable consequences. Verification of compliance is required } \\
\text { prior to reactor operation. }\end{array}$ & $\begin{array}{l}\text { The potential reactivity insertion from experiment failure is within } \\
\text { the reactivity limits for the fault categories as discussed in Section } 6 \text {. }\end{array}$ \\
\hline UFSAR 10.3.5.1.2 Flux Trap Cascading & \\
\hline $\begin{array}{l}\text { Experiments in a reactor flux trap that generate significant heating } \\
\text { and transfer the heat to the associated coolant very rapidly have } \\
\text { the capability of adding additional positive reactivity during a } \\
\text { power transient. This effect is known as cascading. Analyses in } \\
\text { Chapter } 15 \text { (Accident Analyses) establish a reactivity insertion } \\
\text { envelope for this effect. The cascading reactivities used in } \\
\text { Chapter } 15 \text { were developed from the previous analyses of a } 0.75 \$ \\
\text { step insertion (EG\&G } 1994 \mathrm{~b} \text { ). The cascade reactivity envelope as }\end{array}$ & This experiment is not located in a flux trap. \\
\hline
\end{tabular}


MOX FUEL IRRADIATION ESAP

DAR No.: MOX-ESAP-3 May 2000

\begin{tabular}{|c|c|}
\hline Requirement & Compliance \\
\hline \multicolumn{2}{|l|}{$\begin{array}{l}\text { defined in Chapter } 15 \text { is } 0.05 \$ \text { in } 0.13 \text { seconds for Condition } 2 \\
\text { events, } 0.03 \$ \text { in } 0.04 \text { seconds for Condition } 3 \text { events and } 0.17 \$ \text { in } \\
0.15 \text { seconds for Condition } 4 \text { events. }\end{array}$} \\
\hline $\begin{array}{l}\text { UFSAR 10.3.5.1.3 Flux Trap Reactivity Feedback } \\
\text { The positive reactivity feedback from the flux traps was } \\
\text { considered significant in the analyses of the PCS flow coast down } \\
\text { event during a loss of commercial power (Chapter 15.3, Decrease } \\
\text { in Reactor Primary Coolant Flow Rate) (Terry 1994). The } \\
\text { reactivity feedback from the flux traps shall not exceed the values } \\
\text { of the analyses without additional analyses to demonstrate } \\
\text { compliance with the plant protection criteria. The verification of } \\
\text { the reactivity feedback must be completed prior to reactor } \\
\text { operation. }\end{array}$ & This experiment is not located in a flux trap. \\
\hline \multicolumn{2}{|l|}{ UFSAR 10.3.5.2.1 Experiments Cooled by Reactor Primary Coolant } \\
\hline $\begin{array}{l}\text { During reactor operation in the pressurized mode with reactor } \\
\text { power greater than } 3 \mathrm{MW} \text {, when reactor primary coolant is used } \\
\text { to cool surfaces of experiments, the following thermal-hydraulic } \\
\text { criteria are used to assure no flow instability occurs during normal } \\
\text { transient conditions: } \\
\text { (i) The DNB ratio is always greater than two; or the heat flux at } \\
\text { the hottest spot is lower, by at least three standard deviations, than } \\
\text { the DNB heat flux computed for the condition of reactor primary } \\
\text { coolant pumps coast down to emergency flow assuming reactor } \\
\text { power is initially } 250 \mathrm{MW} \text { and a PPS scram occurs. }\end{array}$ & $\begin{array}{l}\text { The thermal analysis for two pump operation presented in Ott 1997, } \\
\text { results in the following: } \\
\frac{\text { DNBR }}{6.54(>2.0)} \\
\text { Limits are given in parenthesis } \\
\text { These values were calculated for coastdown of the primary system } \\
\text { scenario as a result of loss of commercial power to the site during } \\
\text { two pump operation with NW lobe power at } 34 \mathrm{MW} \text {, which is the } \\
\text { maximum allowable lobe power for the NW lobe. }\end{array}$ \\
\hline $\begin{array}{l}\text { (ii) The rise in bulk reactor primary coolant temperature along } \\
\text { the experiment hot track is less than half the value that would } \\
\text { cause flow instability; or the highest reactor primary coolant } \\
\text { temperature is lower, by at least three standard deviations, than } \\
\text { the value that would cause the flow to become unstable, computed } \\
\text { under the same condition as (i) above. } \\
\text { (iii) Any perturbation by an experiment of reactor primary } \\
\text { coolant flow in a fuel element shall not cause the protection } \\
\text { criteria of Chapter } 15 \text { (Accident Analyses) to be exceeded. }\end{array}$ & $\begin{array}{l}\text { (iii) No credible mechanisms have been identified by which this } \\
\text { experiment could possibly perturb the coolant flow in a reactor fuel } \\
\text { element. }\end{array}$ \\
\hline \multicolumn{2}{|l|}{$\begin{array}{l}\text { Verification of the thermal hydraulic criteria is required prior to } \\
\text { reactor operation. }\end{array}$} \\
\hline \multicolumn{2}{|l|}{ UFSAR 10.3.5.3 Gas Leakage } \\
\hline $\begin{array}{l}\text { During reactor operation, experiments must not leak gas into the } \\
\text { reactor such that the ATR Plant Protection Criteria specified in } \\
\text { Chapter } 15 \text { (Accident Analyses) are exceeded. }\end{array}$ & $\begin{array}{l}\text { Gas release potential from this MOX experiment is limited to the } \\
\text { helium and generated fission product gases. The peak fission } \\
\text { product gas volume from all nine ( } 9 \text { ) capsule assemblies is small ( } 1.8 \\
\text { cubic inches), such that if all was released simultaneously, it would } \\
\text { not exceed the consequences of a gas leakage fault as discussed in } \\
\text { UFSAR Section } 15.10 .4 \text {. In addition, these few cubic inches of } \\
\text { gases would be swept through the PCS and largely dispersed before } \\
\text { potentially entering ATR fuel or flux traps. Each capsule assembly } \\
\text { has been designed as a Class } 1 \text { vessel per the appropriate rules as } \\
\text { specified in subsection NB, Section III, Division } 1 \text { of the ASME } \\
\text { B\&PV Code. Therefore, leakage from a capsule is a Condition } 3 \\
\text { fault. Based on the best estimate analysis, Hodge } 1997 \mathrm{~b} \text {, fuel pin } \\
\text { gas plenum pressure is calculated to be } 131 \text { psia (at } 30,000 \\
\text { MWD/MT), which is less than the normal core inlet pressure of } \\
\text { about } 360 \text { psig. }\end{array}$ \\
\hline
\end{tabular}




\section{SAFETY ANALYSIS}

The ESAP is based on irradiation of the MOX experiment in the reactor I-24 hole. Irradiation in any other small I-hole will require a revision of this ESAP. The results of the analyses discussed in this section are based on the Model-1 basket assembly. However, the results are also valid for the Model-2 basket assembly (Ambrosek 1998b).

Steps A through XA were previously completed.

\subsection{Assembling of the Test Assembly on the ATR Main Floor}

Prior to assembling the test assembly on the ATR main floor, a dry run was performed in the HCF using the basket assembly and the nine capsule assemblies. The purpose of this dry run was to provide training and to determine the timing requirement as well as work out any unforeseen problem(s). The capsule assemblies were handled in the presence of qualified nuclear material handlers. The ATR main floor is part of the ATR Criticality Control Area (CCA). The total amount of fissile material in the nine capsule assemblies is about $35 \mathrm{~g} \mathrm{Pu}$ and $2 \mathrm{~g} \mathrm{U}^{235}$. Over 1000 capsule assemblies, fully reflected, would be required in the optimum geometry to achieve criticality (Ryskamp 1997). No other fissile material movement was allowed on the ATR main floor during assembling of the test assembly.

The following limitations and definitions were also implemented during the experiment assembly on the ATR main floor: 1) only one MOX capsule at a time would be removed from the $6 \mathrm{M}$ drum and transferred into the basket assembly, 2) the open $6 \mathrm{M}$ drum would be considered approved storage for the MOX capsules as long as the capsule transfer process continues until the experiment is assembled and all nine capsules have been removed from the drum, and 3) the basket assembly was considered approved storage for the MOX capsules. Dropping a capsule assembly is considered to be an anticipated event. However, any release is considered to be an extremely unlikely event because of the double encapsulation, and the consequences are low. A large fire during experiment assembly is considered to be an incredible event on the basis of 1 hour stay time on the ATR main floor. Therefore, assembling of the MOX test assembly on the ATR main floor does not pose any unusual threat to workers health and safety.

\subsection{Irradiation of the experiment in the ATR}

Steps E, J, Q, W, and YF Irradiation of the experiment in the ATR

The following Condition 1, 2, 3, and 4 scenarios were analyzed on the basis of nine MOX fuel capsule assemblies in the test assembly. Sample analyses for the Model-2 basket with two pumps operation and 1 fuel capsule assembly (at $12 \mathrm{~kW} / \mathrm{ft}$ LHGR) between 2 dummy capsule assemblies per channel (total 3 fuel capsule assemblies per test assembly, See Figure 7a) have also been performed. The results indicated that the overall fluid temperature rose $11.1^{\circ} \mathrm{F}$ within the test assembly and the minimum DNBR was 14.75 in the case of only one fuel capsule assembly per channel compared to a temperature rise of $27{ }^{\circ} \mathrm{F}$ and minimum DNBR of 8.06 in 
MOX FUEL IRRADIATION ESAP

DAR No.: MOX-ESAP-3 May 2000

the case of three fuel capsule assemblies per channel.(Hodge 2000) The analyses and results were reviewed by the INEEL and were found to be satisfactory. (Ambrosek 2000). Therefore, the Phase III, Part2, experiment is bounded by the previous analyses.

\subsubsection{Condition 1 Normal Power Operation in Reactor}

Fission Gas Behavior and Swelling Effects

The fission gas inventory is composed of krypton, xenon, iodine, and cesium. Cs and I originate as independent entities, but subsequently combine to form gas molecules such as $\mathrm{I}_{2}$ and $\mathrm{CsOH}$, and compound CsI, also a gas at high temperature. As these gases accumulate within the fuel matrix, a portion of the total gas inventory will emerge from the pellet surface and enter the void spaces within the confines of the surrounding fuel pin assembly. This escape of the fission gases from the fuel pellets causes pressurization of the fuel pin assembly. The escape fraction depends upon atomic diffusion, gas bubble nucleation, bubble migration, bubble coalescence, interaction of bubbles with structures, and irradiation resolution.

The highest escape fraction for MOX fuel that has been reported in the available literature for a LHGR of $12 \mathrm{~kW} / \mathrm{ft}$ is $21 \%$ (30 to $50 \mathrm{GWd} / \mathrm{MT}$ ). The best estimate expected escape fraction available in the literature is $0.8 \%$ at $30 \mathrm{GWd} / \mathrm{MT}$ for a LHGR of $4.1 \mathrm{~kW} / \mathrm{ft}$. In recognition that the LHGR under consideration $(12 \mathrm{~kW} / \mathrm{ft}$ ) is three times higher (and the desired maximum is 10 $\mathrm{kW} / \mathrm{ft}$ ), the best estimate release rate is set three times higher, at $3 \%$. Thus, an upper bound for the expected pressure (fission gas plus helium) in the fuel pin assembly at a burnup of 30 $\mathrm{GWd} / \mathrm{MT}$ is calculated to be $675 \mathrm{psi}$ (21\% release), and the best estimate value of expected pressure within the hottest fuel pin assembly is calculated to be 114 psi (3\% release) (Hodge 1997b). These calculated pressures are well within the design limit of 1425 psi.

The calculated pellet swelling is expected to close the pellet-to-clad gap at a burnup of 10.6 $\mathrm{GWd} / \mathrm{MT}$. As the burnup continues, the pellet diameter is expected to increase another 1.8 mils, in the process imposing a hoop strain of $0.5 \%$ on the fuel pin wall. Such a small strain can easily be accommodated by normal creep relaxation of the Zircaloy wall at operating temperatures of 300 C (Hodge 1997b).

Although the diameter of the fuel pin wall will be slightly expanded by pellet swelling, the outer surface of the fuel pin will not come into contact with the surrounding stainless steel capsule. Thus, fuel pin swelling is not expected to impose any loading to the capsule wall.

Pellet swelling and normal thermal expansion of the fuel is predicted to increase the total fuel volume by $4.2 \%$. However, all of this added fuel volume is expected to be accommodated by increases in the total fuel pin volume because of the outward expansion of the fuel pin wall and the increased pin length caused by both thermal expansion and irradiation. Thus, fuel pellet swelling is not expected to reduce the volume assumed available for the fission gas that will be generated during the experiment. 
The highest capsule temperatures occur at the fuel radial centerline. The highest temperatures are $1771{ }^{\circ} \mathrm{C}$ within the top half of the top pellet and $1566{ }^{\circ} \mathrm{C}$ within the bottom half of the bottom pellet at a LHGR of $12 \mathrm{~kW} / \mathrm{ft}$ during 2-pump operation. Note that the desired maximum LHGR is $10 \mathrm{~kW} / \mathrm{ft}$, so these analyses are conservative. The melting temperature for $\mathrm{UO}_{2}$ plus 5 weight percent $\mathrm{PuO}_{2}$ is $2813{ }^{\circ} \mathrm{C}$ for fresh fuel and $2653{ }^{\circ} \mathrm{C}$ for fuel at $50 \mathrm{GWd} / \mathrm{MT}$ burnup. The maximum fuel surface temperature is estimated to be less than $600{ }^{\circ} \mathrm{C}$. The $\mathrm{Zr}$ inner surface temperature is calculated to be $\sim 400{ }^{\circ} \mathrm{C}$ and capsule surface temperature is calculated to be $\sim 100{ }^{\circ} \mathrm{C}$. The predicted axial variations in the capsule temperatures are given in Figure 3.5 of Ott 1997. The maximum gas temperature in the fuel pin is calculated to be $1580{ }^{\circ} \mathrm{C}$ in the pellet dish region at a LHGR of $12 \mathrm{~kW} / \mathrm{ft}$. The maximum gas temperature in the capsule assembly is calculated to be $260{ }^{\circ} \mathrm{C}$ in fuel pin-to-capsule annular gap at a LHGR of $12 \mathrm{~kW} / \mathrm{ft}$ (Hodge 1997b, Ott 1997).

\section{Coolant Pressure Drop and Temperature Rise}

Ott (1997) performed thermal hydraulic analyses for normal operation (two- or three-pump). These analyses assumed a linear heat generation rate (LHGR) of $12 \mathrm{~kW} / \mathrm{ft}$ even though the capsules are expected to have LHGRs of 6-10 kW/ft during normal operations (Chang 1998a ).

With three pumps in operation, a pressure drop of 87 psid across the ATR core and experimental test section was calculated. The overall fluid temperature rise was calculated to be $24{ }^{\circ} \mathrm{F}$ within the test assembly and $4.3{ }^{\circ} \mathrm{F}$ in the exterior coolant flow.

With two pumps in operation, a pressure drop of 67 psid across the ATR core and experimental test section was calculated. The overall fluid temperature rise was calculated to be $27^{\circ} \mathrm{F}$ within the test assembly and $4.9^{\circ} \mathrm{F}$ in the exterior coolant flow.

The results of the analyses discussed in this section are based on the Model-1 basket assembly. However, the results are also valid for Model-2 basket assembly (Ambrosek 1998b).

Maximum Power in NW Lobe of 34 MW Operation

The I-24 position is located in the northwest (NW) quadrant of ATR.

Chang (1997) estimated a maximum LHGR of $9.14 \mathrm{~kW} / \mathrm{ft}$ for the test capsules with a NW lobe power of $17 \mathrm{MW}$. For the evaluation at $34 \mathrm{MW}$ lobe power, a LHGR of $18.3 \mathrm{~kW} / \mathrm{ft}$ was used.

Three-pump operation: The minimum DNBR was calculated to be in the capsule flow channels on the surfaces of the capsules at the ends of the fuel stacks. The minimum DNBR is 8.9. The minimum value of the flow stability criterion is 5.13 at the Al-Inconel (Model-1) gap channel exit (Ott 1997). 
MOX FUEL IRRADIATION ESAP

DAR No.: MOX-ESAP-3 May 2000

Two-pump operation: The minimum DNBR was calculated to be in the capsule flow channels on the surfaces of the capsules at the ends of the fuel stacks. The minimum DNBR is 8.06. The minimum value of the flow stability criterion is 4.24 at the Al-Inconel (Model-1) gap channel exit (Ott 1997).

The DNBRs and Flow Instability Ratios are always greater than 2.0 for two or three pump operation, which meets the ATR safety requirements.

\section{Experiment Reactivity}

As discussed in McCracken (1984), a reactivity worth of $1074 \mathrm{~g} \mathrm{U}^{235}$ in a large I-hole was measured to be less than $0.05 \$$. The amount of fissile material ( $35 \mathrm{~g} \mathrm{Pu})$ being introduced in the $\mathrm{I}-24$ hole position for this irradiation is equivalent to $70 \mathrm{~g} \mathrm{U}^{235}$. Therefore, this prompts the conclusion that the reactivity insertion of the MOX experiment assembly is less than $0.01 \$$. This $0.01 \$$ insertion is for a flat power scenario. In a conservative bounding case, $100 \mathrm{MW}$ relative lobe power, reactivity insertion would be limited to $0.04 \$$ (i.e., $0.01 \$ *(100 / 50)$ ).

\subsubsection{Condition 2 Anticipated Events}

The following Condition 2 events are assessed.

Perched Test Assembly

A perched test assembly that falls into place during reactor operation is an anticipated event. The reactivity worth of the MOX test assembly is less than $0.01 \$$, far below the $0.50 \$$ reactivity limit for an anticipated fault. Therefore, a sudden drop in this assembly will not impact ATR operation.

Clad Failure

For the purpose of this ESAP, failure of a fuel pin assembly zircaloy clad is considered to be an anticipated fault. The fuel pin assembly is encapsulated in a 304L stainless steel (SS) ASME B\&PV Code, Section III, Class 1 pressure vessel container as shown in Figure 1. The thermal hydraulic analysis with two-pump operation and an LHGR of $12 \mathrm{~kW} / \mathrm{ft}$ shows that the capsule surface temperature is expected to be less than $100{ }^{\circ} \mathrm{C}$ (Ott 1997). Fission gas leak analysis indicated that the capsule gas plenum essentially remains at local coolant temperature and showed very little variation with almost no gas movement. No release of fission products outside of the stainless steel capsule is expected.

Flow coastdown with two primary pumps initially running

As defined in Polkinghorne (1994), one potential abnormal condition is coastdown of the primary coolant system (PCS) pumps (with an associated reactor scram and with emergency flow) from a NW lobe power of $34 \mathrm{MW}$ with two primary coolant pumps initially running. This accident is initiated by a loss of commercial power to the site. The minimum DNBR for this 
MOX FUEL IRRADIATION ESAP

DAR No.: MOX-ESAP-3 May 2000

event was calculated to be in the capsule flow channels on the surfaces of the capsules at the ends of the fuel stacks. The minimum DNBR is 6.54. The minimum value of the flow stability criterion is 2.66 at the Al-Inconel gap (Model-1) channel exit (Ott 1997). Both of these values are greater than 2.0, which meets the ATR safety requirements. See Ambrosek (1998b) for assessment of the Model-2 basket assembly. No release of fission products is expected in any anticipated event. Therefore, the consequences and risks are acceptable.

The MOX test assembly has been evaluated subjectively for natural convection cooling and for response to a reactivity initiated transient, as related to the ATR TSR (ATR 1998) and the ATR UFSAR (ATR 1999) compliance.

The rationale for requiring a DNBR and FIR greater than 2.0 is that an experiment is assured to have a greater margin of safety than the driver core. This leads to the requirement for assessment at the ATR UFSAR 10.3.5.2.1 (ATR 1999) limits of lobe power for the irradiation position, since the driver core limits are based on lobe power limits. Provided there are no design features that will cause a degradation of natural convection, such as a check valve to restrict reverse flow, the experiment will have a safety margin not less than the driver core for natural convection cooling when the decay heat has a response equivalent or less severe than the driver fuel. The MOX assembly has no reverse flow device to hinder natural convection. Natural convection cooling in the MOX assembly is expected to be better than in an ATR fuel element since a large portion of the operational pressure drop is across an orifice. The friction factor is usually higher for lower velocity flow, while form loss coefficients are essentially the same. The decay heating response in the MOX assembly is essentially the same as the driver fuel (and the heating rates in terms of watts per gram of fuel are always much less in the MOX capsules).

Natural convection cooling for the MOX assembly is bounded by the driver core response.

The argument for the ATR UFSAR 10.3.5.1.1 (ATR 1999) compliance as above also holds for a reactivity initiated event.

The test requirements assure that the experiment will maintain margins greater than the driver core. The evaluations for DNBR and FIR at the maximum lobe power and during a flow coastdown assure that for experiments cooled by primary coolant, the margins are not less than for the driver core.

\subsubsection{Condition 3 Unlikely Events}

Each capsule assembly qualifies as a Class 1 pressure vessel and meets the appropriate rules as specified in subsection NB, Section III, Division 1 of the ASME B\&PV Code. Therefore, failure of a single capsule assembly is defined as an unlikely fault.

In case of an unlikely event, activity in the primary coolant is estimated based on the following assumptions: 
MOX FUEL IRRADIATION ESAP

DAR No.: MOX-ESAP-3 May 2000

- Instantaneous release of $100 \%$ of gaseous fission products from the plenum of the highest burnup capsule assembly (i.e., $3 \%$ of the total fission gas inventory) to the primary coolant,

- Fission gases include $\mathrm{Xe}, \mathrm{Kr}$, I, and Cs,

- Instantaneous homogeneous mixing in the PCS, i.e.; zero decay time,

Total PCS volume $=3.1 \mathrm{E} 8 \mathrm{cc}$.

Using a nominal MOX fuel loading per capsule, an ORIGEN2 calculation of the radioactivity of actinides and fission products of all MOX capsules was performed (Terry, 1998a). Based on the maximum fission gas activity in the highest-burnup capsule assembly, the peak release (see Figure 9) from the failed capsule assembly results in less than $0.4 \mu \mathrm{Ci} / \mathrm{cc}$ increase in the primary coolant activity. Normal primary coolant activity is 0.03 to $0.16 \mu \mathrm{Ci} / \mathrm{cc}$. The reactor primary coolant activity has a limit of $20 \mu \mathrm{Ci} / \mathrm{cc}$. Therefore, failure of a single capsule assembly will not approach the normal PCS activity operating limit. The fission products from plutonium are essentially the same as those from ATR fuel, so the potential stack release consequences from a MOX capsule are enveloped by those from ATR fuel for any unlikely event.

\subsubsection{Condition 4 Extremely Unlikely Events}

Normally, the limiting credible fault associated with an irradiation program is an extremely unlikely, complete flow blockage to the I-hole position. The design of the MOX test assembly is such that it provides several holes strategically located on the test assembly (three 2-inch-long slots exist about 8 inches below the top of the test assembly). Flow blockage at the top of the test assembly may occur, but water would then flow in the slots to cool the MOX capsules. Therefore, water will always cool the capsules because blockage of any one flow path will not result in complete flow blockage.

Simultaneous failure of two or more MOX capsule assemblies is assumed to be an extremely unlikely fault. Failure of a single capsule assembly would result in less than $0.4 \mu \mathrm{Ci} / \mathrm{cc}$ in the primary coolant. Therefore, all nine MOX capsule assemblies can experience simultaneous failures without exceeding the operating limit of $20 \mu \mathrm{Ci} / \mathrm{cc}$.

In the event of MOX fuel melting in the highest burnup capsule assembly, activity in the primary coolant is estimated based on the following assumptions:

Instantaneous release of $21 \%$ of gaseous fission products plus $10 \%$ of the fission product particulates from the highest burnup capsule assembly to the primary coolant,

Fission gases include $\mathrm{Xe}, \mathrm{Kr}$, I, and Cs,

Instantaneous homogeneous mixing in the PCS, i.e., zero decay time,

Total PCS volume $=3.1 \mathrm{E} 8 \mathrm{cc}$. 
MOX FUEL IRRADIATION ESAP

DAR No.: MOX-ESAP-3 May 2000 
MOX FUEL IRRADIATION ESAP

DAR No.: MOX-ESAP-3 May 2000

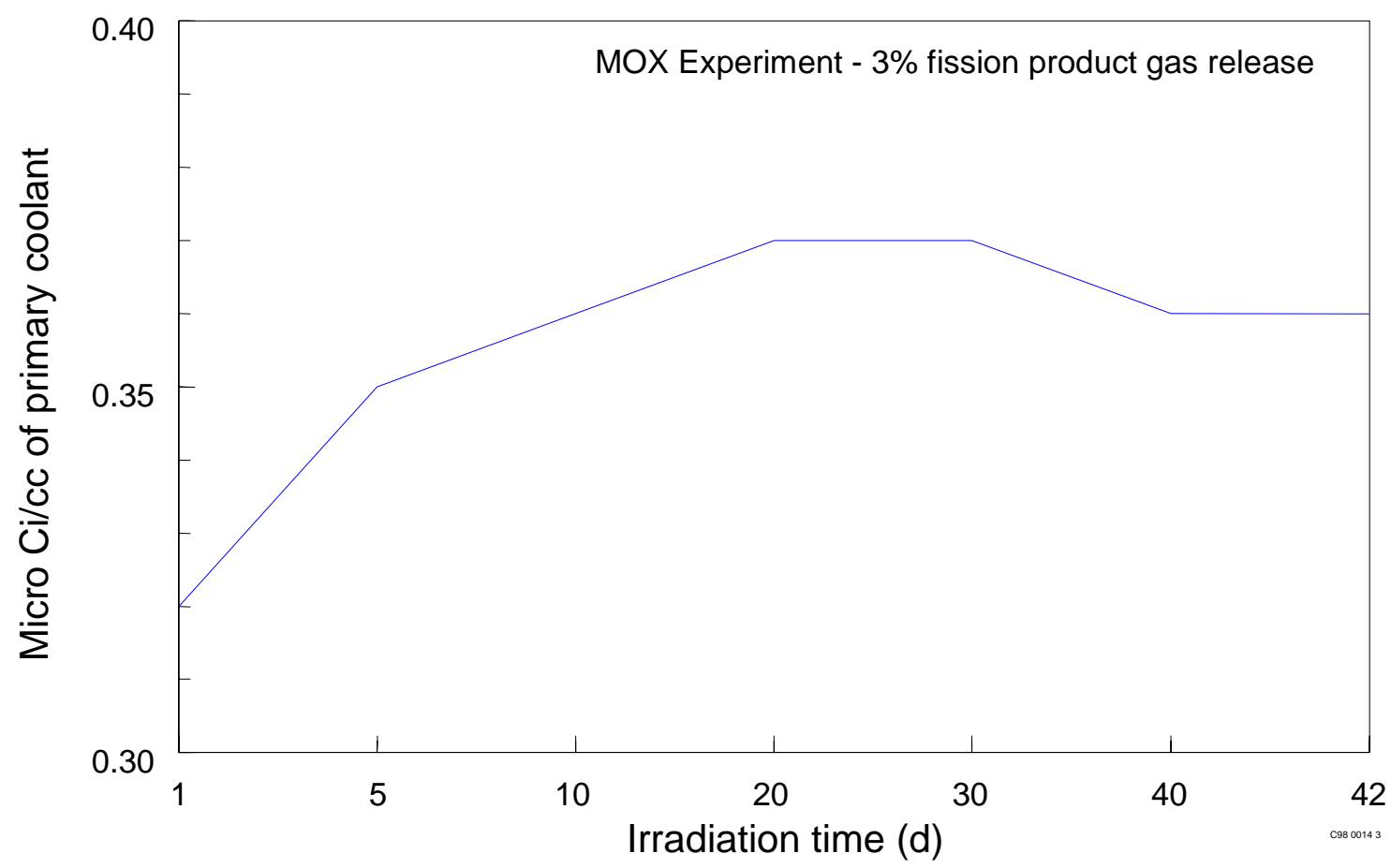

Figure 9. PCS activity - unlikely event 
MOX FUEL IRRADIATION ESAP

DAR No.: MOX-ESAP-3 May 2000

No mechanism for this scenario has been identified. However, if the failure should occur, calculation shows that the maximum increase in the primary coolant activity would be $8 \mu \mathrm{Ci} / \mathrm{cc}$, see Figure 10, which is well below the reactor primary coolant activity limit of $20 \mu \mathrm{Ci} / \mathrm{cc}$.

Fission products generated by plutonium are essentially the same as those generated by the uranium in the ATR fuel. Any fission product release from the MOX capsules is enveloped by potential releases from ATR fuel. For example, the ATR limit on releasing fission product noble gases up the stack is $450 \mathrm{Ci} /$ day. If we assume an instantaneous release of all the fission product gases from the gas plenum in one MOX capsule, directly up the stack with no decay time or filtering in the primary coolant or degassing tank, a maximum of $115 \mathrm{Ci}$ will go up the stack. This is well within the ATR limit for stack release.

Because MOX fuel is $95 \% \mathrm{UO}_{2}, \mathrm{MOX}$ fuel behaves very similar to $\mathrm{UO}_{2}$ fuel in commercial nuclear reactors in both normal and accident conditions. Also note that these capsules are nearly 10 times the density of water and will not float.

\subsection{Canal Activities}

Steps F, G, H, K, L, N, O, P, R , S, U, V, X, Y, Z, ZA, AA, AB, YA, YD, YE, YG, YH, YJ (Canal Activities)

\subsubsection{Condition 1 Normal Operations:}

Any movement of the MOX test assembly within the ATR canal area, or other operations involving the irradiated MOX test assembly, will be performed and controlled under a specific Radiological Work Permit (RWP).

Operations involving the MOX capsule assemblies in the ATR Canal (test assembly loading and unloading) are performed, with monitoring by a Radiation Control Technician (RCT), by personnel wearing dosimeters as specified in the RWP. Personnel exposure rates are controlled by adjusting the depth of the canal working tray, where the capsules are located, as necessary to remain within the levels specified in the RWP. Constant Air Monitors (CAMs) and Remote Area Monitors (RAMs) are also in service as required by the Canal Operating and Maintenance Manual. ALARA principles are applied throughout the operation.

In relation to the MOX experiment being stored in the canal, three event categories (Condition 2, Condition 3, and Condition 4) are considered in the development of this ESAP.

\subsubsection{Condition 2 Anticipated Event:}

Dropping an irradiated MOX capsule to the bottom of the canal

Accidental dropping of a MOX capsule during handling in the ATR canal has been evaluated. A maximum heating rate as reported in Hodge 1997c, at approximately $8 \mathrm{GWd} / \mathrm{MT}$ and after 4 hrs 
MOX FUEL IRRADIATION ESAP

DAR No.: MOX-ESAP-3 May 2000

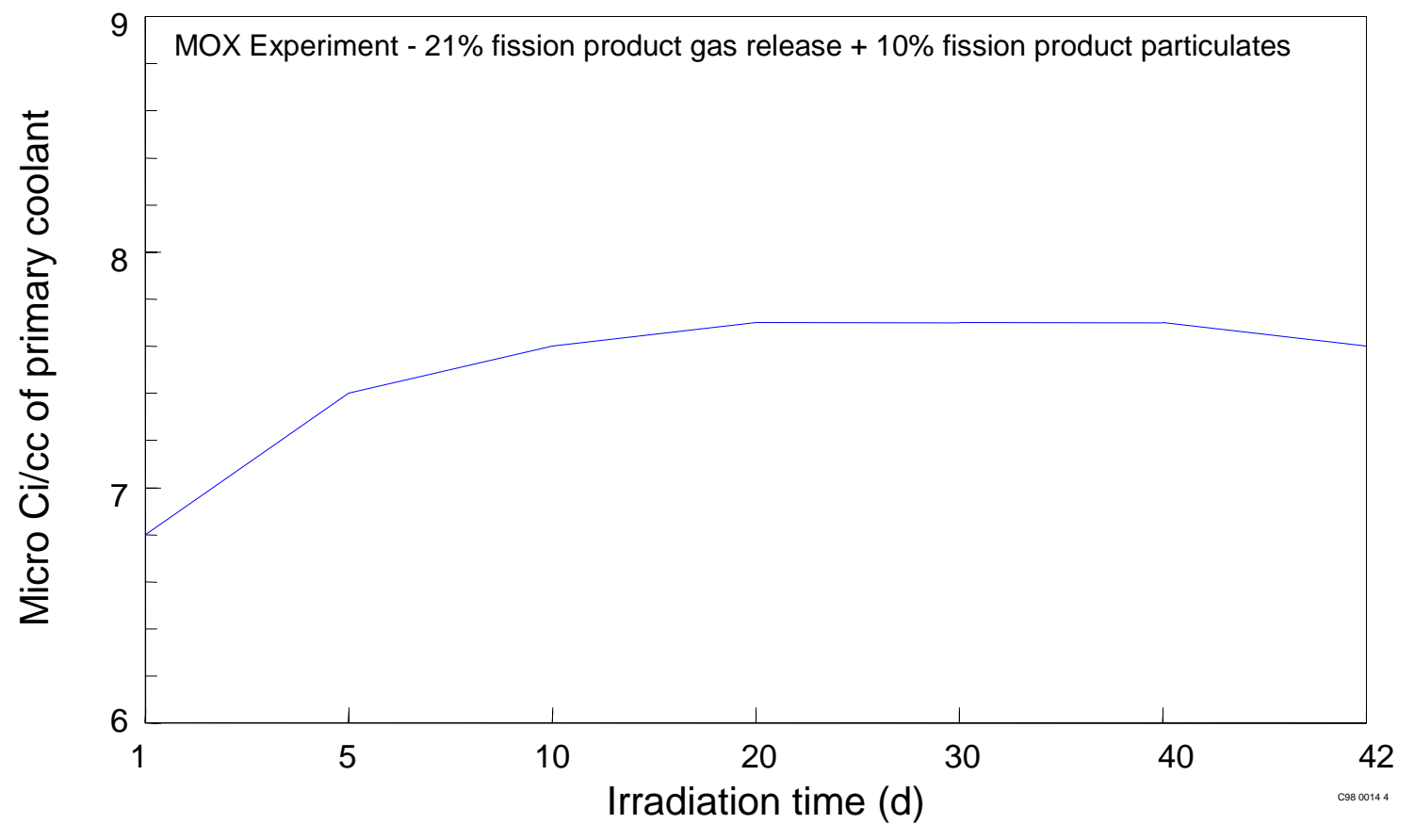

Figure 10. PCS activity - extremely unlikely event 
MOX FUEL IRRADIATION ESAP

DAR No.: MOX-ESAP-3 May 2000

of cooling, was used. The maximum surface temperature is expected to be less than $100 \mathrm{~F}$, and no boiling will occur on the capsule surface (Ambrosek 1997b). This precludes any potential for dryout and temperature excursion. These MOX capsules are nearly 10 times denser than water and will not float. Restrictions will be placed in the Reactor Loading Record and the CRD 16 letter to prohibit transfer of the test assembly out of the reactor and to the canal in less than 4 hours after a reactor scram.

\subsubsection{Condition 3 Unlikely Events:}

Minor damage to a single capsule

The MOX capsule assembly 304L SS outer pressure boundary meets ASME B\&PV Code Section III, Class 1. Minor damage to a single capsule is assumed to be a bounding unlikely event. A release of two percent of the fission products from an ATR fuel plate is assumed to be an unlikely scenario. Total $\mathrm{Pu}$ inventories and two percent of the total fission products in an average fuel plate, $8 \mathrm{hrs}$ after reactor shutdown, are calculated to be $7 \mathrm{Ci}$ and $6,700 \mathrm{Ci}$, respectively (ATR 1999). In the highest-burnup MOX capsule assembly, total peak $\mathrm{Pu}$ inventories, and two percent of the total fission products $4 \mathrm{hrs}$ after the shutdown, are calculated to be $2 \mathrm{Ci}$ and $110 \mathrm{Ci}$, respectively. The fission product source from the MOX capsules is much less than that of an ATR fuel plate, so the dose consequences from a MOX capsule are less than from a fuel plate. Therefore, the consequences from the MOX capsule assembly are enveloped in the case of an unlikely event of fission product gas release. (Based on 10\% of gaseous fission products released in the canal with instantaneous mixing and zero decay time in case of an unlikely event, the activity in the Canal is estimated. Using nominal MOX fuel loading per capsule, an ORIGEN2 calculation of the radioactivity of actinides and fission products of a single irradiated capsule was performed. The maximum activity in the canal is calculated to be less than $0.5 \mathrm{Ci} / \mathrm{cc}$ based on the canal water inventory.)

The use of the HCC \#3, GE-100, or GE-2000 cask is governed by ATR DOP 4.8.7, 4.8.36, and 4.8.4 respectively. The consequences of cask-drop unlikely events with any of these casks are within the cask-drop events analyzed in the UFSAR and will not increase as a result of this MOX fuel experiment.

Lifting an irradiated capsule out of the canal water

During the manipulation of the capsule assemblies in the canal on the working tray area, an operator lifting an irradiated assembly up out of the water is an unlikely event. A special canal tool is used to screw into the top of each capsule to lift it out of the test assembly and onto the canal-working tray. The operator may not be aware that a capsule is attached to the end of the tool and could possibly lift it out of the canal water. During capsule manipulation a person from Radiological Control will be present and monitor any work in the canal. It is expected that if the dose rate at the canal working level exceeds the predetermined limit, the work will be stopped and the canal working tray and capsule will be lowered in the canal. It is expected that canal area radiation alarms will also go off, warning personnel in case a capsule is pulled up too far. The movement of the test assembly in the canal is considered no different than movement of the ATR 
MOX FUEL IRRADIATION ESAP

DAR No.: MOX-ESAP-3 May 2000

fuel element, and consequences are bounded by the lifting of an ATR fuel element out of the water.

\subsubsection{Condition 4 Extremely unlikely events:}

Simultaneous minor damage to two capsules or a significant fuel meltdown of one entire capsule

A complete meltdown of an ATR fuel element is assumed to be an extremely unlikely scenario. Total fission products and total $\mathrm{Pu}$ inventories in an average fuel element, $8 \mathrm{hrs}$ after the shutdown, are calculated to be 6.3E6 Ci and 1.37E2 Ci, respectively (ATR 1999). In the highestburnup MOX capsule assembly (assuming the complete meltdown of one capsule), total fission products and total $\mathrm{Pu}$ inventories, $4 \mathrm{hrs}$ after the shutdown, are calculated to be $5500 \mathrm{Ci}$ and $2 \mathrm{Ci}$, respectively. The fission product and plutonium sources from the MOX capsule are much less than that of an ATR fuel element, so the dose consequences from a MOX capsule are less than from an ATR fuel element. Therefore, the consequences from the MOX capsule assembly are enveloped in the case of an extremely unlikely event. (Based on 100\% of gaseous fission products and 10\% of the fission product particulate released in the canal in the case of an extremely unlikely event, the activity in the Canal is estimated. Using a nominal MOX fuel loading per capsule, an ORIGEN 2 calculation of the radioactivity of actinides and fission products of a single irradiated capsule was performed. The maximum activity in the canal is calculated to be $3.0 \mathrm{Ci} / \mathrm{cc}$ based on the canal water inventory.)

The use of the HCC \#3, GE-100, or GE-2000 cask is governed by the ATR DOP 4.8.7, 4.8.36, and 4.8.4 respectively. The consequences of cask-drop extremely unlikely events with any of these casks are within the cask-drop events analyzed in the UFSAR and will not increase as a result of this MOX experiment.

\subsection{Transport of unirradiated or irradiated capsule assemblies within TRA}

Steps M, PA, XA, ZB, T, and YC Transport of unirradiated or irradiated capsule assemblies within TRA

The transportation of the HCC \#3 cask between TRA HCF and ATR canal is internally controlled by DOP 4.8.19. This DOP specifies the lift as a high consequence lift, the minimum capacity for the forklift, limits the speed on the roadway, requires evaluation of road conditions in winter. These limitations assure that the probability of an upset, that could cause damage to the cask and its contents, is low.

Gentillo (1992) contains an engineering evaluation of HCC \#3 cask. The internal heatup of capsule assemblies has been analyzed by Hawkes (1998) and found to be acceptable relative to heat generation limits noted in Sherick (1992). 
MOX FUEL IRRADIATION ESAP

DAR No.: MOX-ESAP-3 May 2000

All capsule assembly will be sealed in isotope shipping canister during transfer in HCC \#3 cask per DOP 4.8.46. This sealed canister provides additional barrier to prevent release if one of the capsules fails.

\subsection{Cask Handling and Shipping Activity}

Steps PB, X, ZA, ZC, AB, and YB Shipping activity (Cask Handling and HCF)

The safety envelope for cask handling within the ATR is established by the ATR TSR 3.5.5, Cask Handling and Irradiated Fuel Storage (ATR 1998) and the ATR UFSAR (ATR 1999), and cask Certificates of Compliance. The loaded cask will be transported to ORNL per applicable DOE, DOT and NRC requirements.

The GE-100 cask at the TRA HCF will be loaded in accordance with HCF procedures that reflect the facility's operating requirements and cask Certificate of Compliance requirements. The loaded cask will be transported to ORNL per applicable DOE, DOT and NRC requirements. 


\section{PLANT PROTECTION CRITERIA}

This section discusses the four conditions for the Plant Protection Criteria for each of the process steps.

\subsection{Condition 1 Events}

Condition 1: Normal Operation. The condition 1 operations are expected to occur frequently or regularly in the course of reactor operations, refueling or maintenance.

Radiation Exposure Limits - Off-site - 100 mrem/year effective dose equivalent (EDE) and 10 mrem/year EDE from airborne release; Worker - 5 rem/year total effective dose equivalent (TEDE).

Barrier Protection Limits - The integrity of the ATR fuel cladding is not challenged in Condition 1 except for limited clad defects.

\subsubsection{Irradiate the test assembly}

Steps E, J, Q, W, and YF - Irradiate the test assembly

Radiation Exposure - There are no identified Condition 1 events associated with irradiating the MOX capsules experiment that could cause off-site exposure. To limit worker exposure, RADCON controls for all of the handling activities are performed in accordance with the Radiation Protection Manual.

Barrier Protection - There have been no Condition 1 events associated with experiment irradiation that have been identified that could possibly lead to ATR fuel cladding damage.

\subsubsection{Canal Activities}

Steps F, I, K, R, Y, and YG - Transfer the test assembly to Canal

Steps H, O, V, and YE - Insert the test assembly in the Reactor

Steps G, and I - Replace the test assembly flux monitors

Steps L, N, S, U, Z, YD, and YH - Disassemble/assemble the test assembly on the working tray in the ATR Canal

Radiation Exposure - There are no identified Condition 1 events associated with the canal activity steps listed as above that could cause off-site exposure. To limit worker exposure, RADCON controls for all of the handling activities are performed in accordance with the Radiation Protection Manual. Operations involving the MOX capsule assemblies and the MOX 
MOX FUEL IRRADIATION ESAP

DAR No.: MOX-ESAP-3 May 2000

test assembly are performed with monitoring by a Radiological Control Technician (RCT) as specified in the Radiological Work Permit (RWP).

Barrier Protection - No Condition 1 events associated with disassembling and assembling the test assembly on the working tray in the ATR canal have been identified that could possibly lead to damage to the fuel cladding.

\subsubsection{Transfer unirradiated or irradiated MOX fuel and dummy capsule assemblies and basket assembly.}

Steps M, PA, PB, T, XA, X, ZB, ZC, YB, YC, AB, and ZA - Transfer unirradiated or irradiated MOX fuel and dummy capsule assemblies and basket assembly

Note: The following assessment of Plant Protection Criteria only applies to the specified process steps after the capsules enter the ATR facility. Once the shipping container leaves the ATR, the applicable Department of Transportation (DOT) Code of Federal Regulations (CFR) or DOP (for HCC \#3) control the shipment, and this experiment is not under the control of the ATR UFSAR.

Radiation Exposure - There are no identified Condition 1 events associated with transferring unirradiated or irradiated MOX fuel, dummy capsule assemblies, and basket assemblies that could cause off-site exposure. To limit worker exposure, RADCON controls for all of the handling activities are performed in accordance with the Radiation Protection Manual.

Barrier Protection - There are no Condition 1 events associated with transferring unirradiated or irradiated MOX fuel, dummy capsule assemblies, and basket assemblies that have been identified that could possibly lead to damage to the ATR fuel cladding.

\subsubsection{Store the irradiated capsule assemblies in the ATR Canal}

Steps P, X, AA, and YA - Store the irradiated capsule assemblies in the ATR Canal

Radiation Exposure - There are no identified Condition 1 events associated with storage of the irradiated capsule assemblies and the loading of the shipping cask that could cause off-site exposure. To limit worker exposure, RADCON controls for all of the handling activities are performed in accordance with the Radiation Protection Manual.

Barrier Protection - There are no Condition 1 events associated with storage of the irradiated capsule assemblies and the loading of the shipping cask that have been identified that could possibly lead to damage to the ATR fuel cladding. 


\subsection{Condition 2 Faults}

Condition 2: Anticipated Faults. The condition 2 anticipated fault is an off-normal condition that is expected to occur once or more during the lifetime of the facility due to an expected single fault.

Radiation Exposure Limits - Off-site - 0.5 rem/year TEDE; Worker - 5 rem/year TEDE.

Barrier Protection Limits - No rupture of the fuel plate cladding is allowable unless the clad failure is the initiating fault. For canal accidents no melting of the fuel plate cladding is allowed.

\subsubsection{Irradiate the test assembly}

Steps E, I, J, Q, W and YF - Irradiate the test assembly

Radiation Exposure - There are no identified Condition 2 faults associated with irradiating the MOX capsules experiment that could cause off-site exposure. To limit worker exposure, RADCON controls for all of the handling activities are performed in accordance with the Radiation Protection Manual.

Barrier Protection - There have been no Condition 2 faults associated with experiment irradiation that have been identified that could possibly lead to ATR fuel cladding damage. The reactivity worth for the experiment was calculated to be less than $0.01 \$$.

\subsubsection{Canal Activities}

Steps F, I, K, R, Y, and YG - Transfer the test assembly to Canal

Steps H, O, V, and YE - Insert the Test Assembly in the Reactor

Steps G, and I - Replace the test assembly flux monitors

Steps L, N, S, U, Z, YD, and YH - Disassemble/assemble the test assembly on the working tray in the ATR Canal

Radiation Exposure - There are no identified Condition 2 faults associated with the canal activities listed in steps above that could cause off-site exposure. To limit worker exposure, RADCON controls for all of the handling activities are performed in accordance with the Radiation Protection Manual. Operations involving the MOX capsule assemblies and the MOX test assembly are performed with monitoring by a RCT as specified in the RWP.

Accidental dropping of a MOX capsule during handling in the ATR canal has been evaluated. A maximum heating rate as reported in (Hodge, 1997c), at approximately 8GWd/MT and after four hours of cooling, was used. The maximum surface temperature is expected to be less than $100 \mathrm{~F}$, 
MOX FUEL IRRADIATION ESAP

DAR No.: MOX-ESAP-3 May 2000

and no boiling will occur on the capsule surface (Ambrosek, 1997b). This precludes any potential for dry out and temperature excursion. These MOX capsules are nearly ten times denser than water and will not float.

Barrier Protection - There are no Condition 2 faults associated with disassembling and assembling the test assembly on the working tray in the ATR canal that have been identified that could possibly lead to damage to the ATR fuel cladding. Dropping a MOX capsule assembly or the MOX test assembly as it is handled will not damage ATR fuel element cladding, as the fuel elements are stored in a different section of the canal located away from the working tray.

\subsubsection{Transport of unirradiated and irradiated capsule assemblies and basket assembly}

Steps M, PA, PB, T, XA, X, ZB, ZC, YB, YC, AB, and ZA - Transport of unirradiated and irradiated capsule assemblies and basket assembly

Note: The following assessment of Plant Protection Criteria only applies to the specified process steps after the capsules enter the ATR facility. Once the shipping container leaves the ATR, the applicable Department of Transportation (DOT) Code of Federal Regulations (CFR), or DOP (for HCC \#3) control the shipment, and this experiment is not under the control of the ATR UFSAR.

Radiation Exposure - There are no identified Condition 2 events associated with transferring unirradiated or irradiated MOX fuel, dummy capsule assemblies, and basket assemblies that could cause off-site exposure. To limit worker exposure, RADCON controls for all of the handling activities are performed in accordance with the Radiation Protection Manual.

Barrier Protection - There are no Condition 2 events associated with transferring unirradiated or irradiated MOX fuel, dummy capsule assemblies, and basket assemblies that could cause off-site exposure. Dropping any MOX capsule assembly as it is handled will not damage ATR fuel element cladding as the fuel elements are required to be properly stored upright in either the fuel annulus, fuel storage grids, or the fuel storage baskets in the vessel.

\subsubsection{Store the irradiated capsule assemblies in the ATR Canal}

Steps P, X, AA, and YA - Store the irradiated capsule assemblies in the ATR Canal

Radiation Exposure - There are no identified Condition 2 faults associated with storage of the irradiated MOX capsule assemblies and the loading of the shipping cask that could cause off-site exposure. To limit worker exposure, RADCON controls for all of the handling activities are performed in accordance with the Radiation Protection Manual.

Barrier Protection - There are no Condition 2 faults associated with storage of the irradiated MOX capsule assemblies and the loading of the shipping cask that have been identified that could possibly lead to damage to the ATR fuel cladding. 


\subsection{Condition 3 Faults}

Condition 3: The Condition 3, unlikely faults, are faults that may occur infrequently during the life of the plant.

Radiation Exposure Limits - Off-site and evacuation worker - 6.25 rem whole body and 75 rem thyroid dose.

Barrier Protection Limits - The reactor primary coolant pressure boundary must be maintained unless its failure is the initiator. No large releases of uranium or fission products to the primary coolant system will occur.

\subsubsection{Irradiate the test assembly}

Steps E, I, J, Q, W and YF - Irradiate the test assembly

Radiation Exposure - There are no identified Condition 3 faults associated with irradiating the MOX capsules experiment that could cause unacceptable off-site exposure. To limit worker exposure, RADCON controls for all of the handling activities are performed in accordance with the Radiation Protection Manual. The stack release consequences for the MOX test assembly are enveloped by those from the ATR fuel for any unlikely events.

Barrier Protection - There have been no Condition 3 faults associated with experiment irradiation that have been identified that could possibly lead to ATR primary coolant pressure boundary damage. No Condition 3 faults associated with MOX capsule irradiation that have been identified that could possibly lead to large releases of uranium or fission products to the primary coolant. See Section 6.2.3 for discussion of failure of a single capsule assembly.

\subsubsection{Canal Activities}

Steps F, I, K, R, Y, and YG - Transfer the test assembly to Canal

Steps H, O, V, and YE - Insert the Test Assembly in the Reactor

Steps G, and I - Replace the test assembly flux monitors

Steps L, N, S, U, Z, YD, and YH - Disassemble/assemble the test assembly on the working tray in the ATR Canal

Radiation Exposure - There are no identified Condition 3 events associated with disassembling and assembling the MOX test assembly on the working tray in the ATR canal that could cause unacceptable off-site exposure. To limit worker exposure, RADCON controls for all of the handling activities are performed in accordance with the Radiation Protection Manual. Operations involving the MOX capsule assemblies and the MOX test assembly are performed 
MOX FUEL IRRADIATION ESAP

DAR No.: MOX-ESAP-3 May 2000

with monitoring by a Radiological Control Technician (RCT) as specified in the Radiological Work Permit (RWP).

The total amount of $\mathrm{Pu}$ and fission products releasable from the MOX test assembly experiment is bounded by the ATR fuel for any unlikely event. See Section 6 for an assessment of a fault involving lifting an irradiated capsule out of the canal.

Barrier Protection - There are no Condition 3 events associated with disassembling and assembling the MOX test assembly on the working tray in the ATR canal that have been identified that could possibly lead to damage to the ATR primary coolant pressure boundary.

\subsubsection{Transport of unirradiated and irradiated capsule assemblies and basket assemblies}

Steps M, PA, PB, T, XA, X, ZB, ZC, YB, YC, AB, and ZA - Transport of unirradiated and irradiated capsule assemblies and basket assembly

Note: The following assessment of Plant Protection Criteria only applies to the specified process steps after the capsules enter the TRA facility. Once the shipping container leaves the ATR, the applicable Department of Transportation (DOT) Code of Federal Regulations (CFR), or DOP (for HCC \#3) control the shipment, and this experiment is not under the control of the ATR UFSAR.

Radiation Exposure - There are no identified Condition 3 faults associated with transferring unirradiated or irradiated MOX fuel, dummy capsule assemblies, and basket assemblies that could cause unacceptable off-site exposure. To limit worker exposure, RADCON controls for all of the handling activities are performed in accordance with the Radiation Protection Manual.

Barrier Protection - There are no identified Condition 3 faults associated with transferring unirradiated or irradiated MOX fuel, dummy capsule assemblies, and basket assemblies that could possibly lead to damage to the ATR primary coolant pressure boundary.

\subsubsection{Store the irradiated capsule assemblies in the ATR Canal}

Steps P, X, AA, and YA - Store the irradiated capsule assemblies in the ATR Canal

The following cask handling and fuel element damage faults have been classified as Condition 3 faults (ATR 1999):

1. Dropping a heavy cask from an elevation of less than one foot above the canal floor or other small or limited failure of the storage canal.

2. Dropping a heavy cask from one foot above parapet within the restricted cask-lifting areas of the canal.

3. Dropping a heavy cask onto the floor north of the canal.

4. Minor damage to one fuel element in the canal with a minor fission product release. 
As shown in ATR UFSAR Chapter 15, these faults will meet the ATR Plant Protection Criteria for primary coolant pressure boundary protection and radiation exposure if the cask handling requirements in the ATR TSR and UFSAR are followed. Compliance with the ATR TSR and UFSAR for this experiment is demonstrated in Section 5 of this ESAP.

Radiation Exposure - There are no identified Condition 3 faults associated with storage of the irradiated capsule assemblies and the loading of the shipping cask that could cause unacceptable off-site exposure. To limit worker exposure, RADCON controls for all of the handling activities are performed in accordance with Radiation Protection Manual.

During the manipulation of the capsule assemblies in the canal on the working tray area, an operator lifting an irradiated assembly up out of the water, is an unlikely event. A special canal tool is used to screw into the top of each capsule to lift it out of the test assembly and onto the canal working tray. The operator may not be aware that a capsule is attached to the end of the tool and could possibly lift it out of the canal water. During capsule manipulation, a person from Radiological Control will be present and monitor any work in the canal. It is expected that if the dose rate at the canal working level exceeds the predetermined limit, the work will be stopped and the canal working tray and capsule will be lowered in the canal. It is expected the canal area radiation alarms will also go off, warning personnel in case a capsule is pulled up too far. The movement of the test assembly in the canal is considered no different than movement of the ATR fuel element, and consequences are bounded by the lifting of an ATR fuel element out of the water.

Minor damage to a single MOX capsule has been established as a bounding Condition 3 fault (which is enveloped by the UFSAR fault for fuel element damage, noted above). See the MOX capsule damage assessment in Section 6.3.2.

Barrier Protection - There are no Condition 3 events associated with storage of the irradiated capsule assemblies and the loading of the shipping cask that have been identified that could possibly lead to damage to the ATR primary coolant pressure boundary.

\subsection{Condition 4 Faults}

Condition 4: The condition 4, Extremely Unlikely Faults, are low-probability faults that are not expected to occur but are postulated because their consequences include the potential for release of significant quantities of radioactive material.

Radiation Exposure Limits - Off-site and evacuation worker - 25 rem whole body and 300 rem thyroid dose.

Barrier Protection Limits - The primary coolant pressure boundary must be maintained unless its failure is the initiator, and the reactor confinement must not be damaged. 


\subsubsection{Irradiate the test assembly}

Steps E, I, J, Q, W, and YF - Irradiate the test assembly

Radiation Exposure - There are no identified Condition 4 faults associated with irradiating the MOX capsules experiment that could cause unacceptable off-site exposure. To limit worker exposure, RADCON controls for all of the handling activities are performed in accordance with the Radiation Protection Manual. The release consequences from the experiment are enveloped by those from ATR fuel for any extremely unlikely events. See Section 6 (Simultaneous failure of two MOX capsules).

Barrier Protection - There have been no Condition 4 faults associated with MOX test assembly irradiation that have been identified that could possibly lead to ATR primary coolant pressure boundary or confinement damage.

\subsubsection{Canal Activities}

Steps F, I, K, R, Y, and YG - Transfer the test assembly to Canal

Steps H, O, V, and YE - Insert the Test Assembly in the Reactor

Steps G, and I - Replace the test assembly flux monitors

Steps L, N, S, U, Z, YD, and YH - Disassemble/assemble the test assembly on the working tray in the ATR Canal

Radiation Exposure - There are no identified Condition 4 events associated with disassembling and assembling the test assembly on the working tray in the ATR canal that could cause off-site exposure. To limit worker exposure, RADCON controls for all of the handling activities are performed in accordance with Radiation Protection Manual. Operations involving the MOX capsule assemblies and the MOX test assembly are performed with monitoring by a RCT as specified in the RWP.

The Condition 4 events of simultaneous minor damage to two capsules or a significant fuel meltdown of one entire capsule are discussed in Section 6.

The total amount of $\mathrm{Pu}$ and fission products releasable from the MOX experiment is bounded by the ATR fuel for any extremely unlikely event.

Barrier Protection - There has been no Condition 4 faults associated with disassembling and assembling the MOX test assembly on the working tray in the ATR canal that have been identified that could possibly lead to damage to the ATR primary coolant pressure boundary or confinement damage. 
MOX FUEL IRRADIATION ESAP

DAR No.: MOX-ESAP-3 May 2000

\subsubsection{Transport of unirradiated and irradiated capsule assemblies and basket assemblies}

Steps M, PA, PB, T, XA, X, ZB, ZC, YB, YC, AB, and ZA - Transport of unirradiated and irradiated capsule assemblies and basket assembly

Note: The following assessment of Plant Protection Criteria only applies to the specified process steps after the capsules enter the ATR facility. Once the shipping container leaves the ATR, the applicable DOT CFR regulations, or DPO (for HCC \#3) control the shipment and this experiment is not under the control of the ATR UFSAR.

Radiation Exposure - There are no identified Condition 4 faults associated with transferring unirradiated or irradiated MOX fuel, dummy capsule assemblies, and basket assemblies that could cause unacceptable off-site exposure. To limit worker exposure, RADCON controls for all of the handling activities are performed in accordance with the Radiation Protection Manual.

Barrier Protection - There are no Condition 4 faults associated with transferring unirradiated or irradiated MOX fuel, dummy capsule assemblies, and basket assemblies that has been identified that could possibly lead to damage to the ATR primary coolant pressure boundary or confinement damage.

\subsubsection{Store the irradiated capsule assemblies in the ATR Canal}

Steps P, X, AA, and YA - Store the irradiated capsule assemblies in the ATR Canal and ship to Oak Ridge National Laboratory (ORNL)

Radiation Exposure - There are no identified Condition 4 events associated with storage of the irradiated MOX capsule assemblies and the loading of the shipping cask that could cause unacceptable off-site exposure. To limit worker exposure, RADCON controls for all of the handling activities are performed in accordance with the Radiation Protection Manual. The total amount of $\mathrm{Pu}$ and fission products releasable from the MOX experiment is bounded by the ATR fuel for any extremely unlikely event. The extremely unlikely events of simultaneous minor damage to two capsules or a significant fuel meltdown of one entire capsule are discussed in Section 6.

Barrier Protection - There are no Condition 4 faults associated with storage of the irradiated MOX capsule assemblies and the loading of the shipping cask that have been identified that could possibly lead to damage to the ATR primary coolant pressure boundary or confinement damage. 


\section{UNREVIEWED SAFETY QUESTIONS}

Operation with the MOX capsule experiment is within the safety envelope of the ATR TSR and the UFSAR as demonstrated in the TSR/UFSAR Compliance Table, and explained in detail in this Experiment Safety Assurance Package. The conduct of this experiment:

1. Does not change the probability of occurrence of the accidents evaluated in the safety envelope.

2. Does not change the consequences of the accidents evaluated in the safety envelope.

3. Does not change the probability of occurrence of a malfunction of equipment important to safety, evaluated in the safety envelope.

4. Does not change the consequences of a malfunction of equipment important to safety, evaluated in the safety envelope.

5. Does not create different types of accidents from those identified in the safety envelope.

6. Does not create different types of malfunctions of equipment important to safety from those identified in the safety envelope.

7. Does not reduce the margin of safety from that identified in the safety envelope.

Therefore, the conduct of this experiment does not constitute an unreviewed safety question. 
MOX FUEL IRRADIATION ESAP

DAR No.: MOX-ESAP-3 May 2000

\section{CONCLUSIONS}

Operation with the MOX capsule experiment is within the safety envelope of the ATR TSR and the UFSAR, and the experiment can proceed as planned. 
MOX FUEL IRRADIATION ESAP

DAR No.: MOX-ESAP-3 May 2000

\section{REFERENCES}

Ambrosek, R. G. (1997a), Letter to S.T. Khericha, Thermal-Hydraulic Evaluation for LWR MOX Irradiation at $12 \mathrm{~kW} / \mathrm{Ft}$, AMB-14-97, December 10, 1997.

Ambrosek, R. G. (1997b), Letter to S. T. Khericha, Maximum Surface Temperature for MOX Capsule Horizontal on Canal Floor, AMB-13-97, December 3, 1997.

Ambrosek, R. G. (1998a), Letter to S. T. Khericha, Review of LWR MOX Test Assembly Flow Test Report, AMB-02-98, January 19, 1998.

Ambrosek, R. G. (1998b), Letter to R. C. Pedersen, Thermal-Hydraulic Review for MOX Fuel Testing for $12 \mathrm{~kW} / \mathrm{ft}$ with Model-2 Test Basket Assembly, AMB-22-98, September 11, 1998

Ambrosek, R. G. (2000), Letter to S. T. Khericha, Operation of MOX Experiment with Stainless Steel Slugs, AMB-02-00, April 27, 2000.

ATR, 1998, Advanced Test Reactor Technical Safety Requirements, Issue 4, Rev. 3, dated UPDATE 1998.

ATR, 1999, Advanced Test Reactor Upgraded Final Safety Analysis Report, Rev. 1999-AU, dated July 1, 1999.

Bayless, P. D. (1998), Air Cooling Analysis of MOX Test Assembly, PDB-01-98, March 17, 1998.

Boston, R. D., Letter to J. M. Ryskamp, Criticality Safety of MOX Fuel Pins in Advance Test Reactor Basket Assembly, RDB-16-98, June 3, 1998

Chang, G. S. (1997), Pre-Irradiation Physics Analysis of Fuel Capsule Fission Rates and Test Assembly Total Heat Rate Distribution, Attachment 7 of Capsule Design Review Meeting Task 7.2 LWR In-Pile Testing, March 12, 1997, S. A. Hodge, ORNL/MD/LTR-86, June 1997.

Chang, G. S. (1998a), Letter to J. M. Ryskamp, Pre-Insertion Physics Analysis of Fuel Capsule Fission Heat Rates and Test Assembly Total Heat Rate Distributions, ORMOX-GSC-01-98, January 23, 1998.

Chang, G. S. (1998b), Letter to J. M. Ryskamp, LHGRS of 9 MOX Fuel Capsules with AL and Inconel (80 Mil) Shields for cycle 118A Insertion,-- ORMOX-GSC-28-98, September 15, 1998

Chang, G. S. (2000), Letter to R. C. Pedersen, MCNP-Calculated MOX Fuel Capsule Burnup and LHGR During Phase-III, Part 2 Irradiation,- ORMOX-GSC-07-00, March 9, 2000 
MOX FUEL IRRADIATION ESAP

DAR No.: MOX-ESAP-3 May 2000

Chidester, K. M. (1998), Letter to J. M. Ryskamp, NMT-9/98-012, January 13, 1998.

Cooper C. D. (1998), Letter to J. M. Ryskamp, Quality Certification for the Mixed Oxide (MOX) Fuel Test Assembly, CDC-01-98, January 1998.

Corum, J. E. (1997), Design Calculations in Support of the Advanced Test Reactor Mixed Oxide (ATR-MOX) Fuel Irradiation Experiment, ORNL/MD/LTR/-92, July 1997.

Corum, J. E., and Luk, K. H. (1998), Addendum-1 to the Design Calculations in Support of the Advanced Test Reactor Mixed Oxide (ATR-MOX) Fuel Irradiation Experiment, X-OE-714 ADDENDUM-1 ORNL/MD/LTR-92, January 1998.

Cowell, B. S. (1996a), Light Water Reactor (LWR) Mixed Oxide Fuel Kickoff Meeting October 8-9, 1996, Oak Ridge, Tennessee, ORNL/MD/LTR-59, November 1996.

Cowell, B. S., and Hodge, S. A. (1997a), Fissile Materials Disposition Program Light Water Reactor Mixed Oxide Fuel Irradiation Test Project Plan, July, (Rev. 1, February 1998).

Cowell, B. S. (1997b), Purchase Order: Mixed-Oxide Capsule Assemblies, ORNL/MD/LTR-90, August 1997.

Cowell, B. S. (1997c), ATR Capsule Assembly Loading and Operation Schedule, ORNL/MD/LTR-91, September, (Rev. 1, February 1998).

Cowell, B. S., and S. A. Hodge (2000), ATR Capsule Assembly Loading and Operation Schedule, ORNL/MD/LTR-91, February 2000, (Rev. 2, February 2000).

DOE (1992a), Nuclear Safety Analysis Reports, DOE Order 5480.23, April 1992.

DOE (1992b), Hazard Categorization and Analysis Techniques for Compliance with DOE Order 5480.23, Nuclear Safety Analysis Reports, Standard 1027-92, December.

Faw, E., (1998) Letter to J. M. Ryskamp, MOX Contribution to Radiation for a Postulated Nuclear Incident at ATR, EMF-01-98, August 1998.

Gentillo, T. A. (1992), EDF TRA-ATR-660, Rev. 1, W.E. \#3 Independent Engineering Evalution, November 1992.

Grover, S. B. (1998a), Final Design Review for the MOX Test Aluminum Filler Assembly /Installation, SBG-10-98, September 23, 1998.

Grover, S. B. (1998b), Final Design Review Closure to the ATR-MOX Capsule Carrier and Capsule Long Insertion Tool, SBG-08-98, September 14, 1998. 
MOX FUEL IRRADIATION ESAP

DAR No.: MOX-ESAP-3 May 2000

Hawkes, G. L. (1998) Letter to S. Khericha, Letter Report on MOX Fuel Thermal Analysis, GLH-03-98, October 1, 1998.

Hawkes, G. L. (1999a), R. G. Ambrosek, W. K. Terry, Thermal Analyses of MOX Fuel Capsule Assembly, INEEL Report INEEL/EXT-99-00489, May 1999.

Hawkes, G. L. (1999b) Letter to R. A. Roesener, Letter Report on MOX Fuel Thermal Analysis for Transport in GE-100 Cask, GLH-03-99, October 4, 1999.

Hodge, S. A. (1997a), Letter to J. M. Ryskamp, Removal of Irradiated MOX Capsules and Related Hardware from the INEEL to ORNL, November 1997.

Hodge, S. A. (1997b), Effects of Fission Gas Release and Pellet Swelling Within the

LWR Mixed Oxide Irradiation Test Assembly Rev.1, ORNL/MD/LTR-83, November 1997.

Hodge, S. A. (1997c), Facsimile to J. M. Ryskamp, Decay Heat and Activity Values for the ATR Capsule, (Brian D. Murphy, ORNL), July 24, 1997.

Hodge, S. A. (1998), Facsimile to R. C. Pedersen, et al., Model 2 Basket Nonconformance Report, ORNL, October 1, 1998.

Hodge, S. A. (2000), E-mail to R. C. Pedersen, Completion of Action Item No. 5, March 9, 2000.

Khericha (1998), R. C. Pedersen, B. L. Barnes, Auditable Safety Analysis for Mixed Oxide (MOX) Fuel Capsules in the TRA-635 Radiography Facility, INEEL Report, INEEL/INT-9701279, January 1998.

McCracken 1984, ATRC Data From the Large I-Hole Fueled Experiment, INEEL, RE-PB-84021, March 29, 1984.

Morton, D. K. (1997), Letter to S. T. Khericha, Structural Review of ATR MOX Fuel Irradiation Experiment, DKM-11-97, December 18, 1997.

Morris, R. N. (2000), J. Giaquinto, S. A. Hodge, MOX Average Power Test Fuel Pellet Initial Gallium Content, ORNL/MD/LTR-182, March 2000.

NCR (1998), Nonconformance Report on Model 2 Aluminum Basket Assembly, NCR Number TRA-OP-M2612 October 1,1998.

NFAC-OSB (1996) Interim Operational Safety Basis Report for Test Reactor Area Nonfacility Nuclear Operations, NFAC-OSB.R00, Rev. o, January 25, 1996.

Ott, L. J. (1997), Thermal/Hydraulic Calculations for the LWR MOX Irradiation Test Assembly at 12kW/ft, ORNL/MD/LTR-85, October 1997. 
MOX FUEL IRRADIATION ESAP

DAR No.: MOX-ESAP-3 May 2000

Ott, L. J. (1998a), Flow Test of the MOX Test Basket Assembly, ORNL/MD/LTR-118, January 1998.

Ott, L. J. (1998b), Flow Test of the Model-2 MOX Test Basket Assembly, ORNL/MD/LTR-149, August 1998.

Pedersen, R.C. (1998a), MOX Capsule Loading Information, RCP-09-98, September 16, 1998.

Pedersen, R.C. (1998b), Hazard Classification for the Transport of Irradiated MOX Capsule in the Hot Cell Carrier 3 (HCC \#3), RCP-10-98, October 26, 1998.

Polkinghorne, S. T. (1994), ATR-SINDA and SINDA-SAMPLE Calculation for Chapter 15 of the ATR Updated UFSAR, EDF TRA-ATR-840, February 1994.

Ryskamp, J. M. (1997), Facsimile to S. A. Hodge, Address MOX Capsules Criticality Concerns, September 22, 1997.

Ryskamp, J. M., S. A. Hodge, and B. S. Cowell (1998), A Mixed Oxide Fuel Irradiation Experiment in the Advanced Test Reactor, Proceedings of the Sixth International Conference on Nuclear Engineering, , CD-ROM Fall Paper, Book of Abstracts Page. 653, San Diego, CA, May 10-15, 1998.

Sherick, M. J. (1992), Letter to D. L. Batt, White Elephant (WE) Cask \#3 Safety Evaluation, MJS-7-92, April 24, 1992.

Terry, W. K. (1998a), Letter to J. M. Ryskamp, MOCUP Calculations of Radionuclide Content in MOX Fuel Capsules to be Irradiated in the Advanced Test Reactor, WKT-02-98, January 28, 1998.

Terry, W. K. (1998b), Letter to J. M. Ryskamp, Clarification of Table Headings, WKT-14-98, October 1, 1998.

Thoms, K. R. (1997a), Design, Functional, and Operational Requirements for the Advanced Test Reactor Mixed Oxide Fuel Irradiation Experiment, RNL/MD/LTR-76, Rev. 1, September 1997.

Thoms, K. R. (1997b), Facsimile to J. M. Ryskamp, Minimum Wall for Weld Defects, December 1997.

Tomberlin, T. A. (1997), MOX Capsule Experiment Relative to ATR Authorization Basis, Tom06-97, November 13, 1997.

Wachs, G. W. (1997), Fabrication, Inspection, and Test Plan for the Advanced Test Reactor (ATR) Mixed-Oxide (MOX) Fuel Irradiation Project, INEEL/EXT-97-01066, November 1997. 
MOX FUEL IRRADIATION ESAP

DAR No.: MOX-ESAP-3 May 2000

West, P. B., (1997a), Letter to Distribution, Report of Design Review, PBW-02-97, August 20, 1997.

West, P. B., (1997b), Letter to Distribution, MOX Test Design Verification Closure, PBW-0397, November 5, 1997.

Wilson, D. F., et al (1997), Interactions of Zircaloy Cladding with Gallium 1997 Status, ORNL/TM-13505, November 1997. 
412.11

$02 / 16 / 2000$

Rev. 05

\section{DOCUMENT MANAGEMENT CONTROL SYSTEM (DMCS) DOCUMENT ACTION REQUEST (DAR)}

Current revision ID:

DAR NO.: MOX-ESAP-3

2. Document title: EXPERIMENT SAFETY ANALYSIS PACKAGE FOR MIXED OXIDE FUEL IRRADIATION IN AN AVERAGE

2. POWER POSITION (I-24) IN THE ADVANCED TEST REACTOR

\begin{tabular}{|l|l|l|l|l|l|l}
\hline 3. Requester: R. C. .PEDERSEN & Phone: 6-2078 & MS: 3419 & E-mail: RP7 & S No.: 51729 \\
\hline
\end{tabular}

4. Type: $\triangle$ Document $\square$ Drawing $\quad$ 5. Type of action: $\square$ Create $\square$ Revise $\square$ Change $\square$ Cancel

6. Field Change: $\triangle$ No $\square$ Yes If Yes, will the change be $\square$ Permanent? or $\square$ Temporary? if temporary, enter the field change duration:

\section{Proposed action}

\begin{tabular}{|c|c|c|c|c|}
\hline Item & $\begin{array}{c}\text { Page } \\
\text { No./Section/Zone }\end{array}$ & \multicolumn{2}{|l|}{ Description } & Justification \\
\hline 1 & & \multicolumn{2}{|c|}{$\begin{array}{l}\text { Orignally the project was planned to end when any capsule } \\
\text { reached a burnup of } 30 \mathrm{GWd} / \mathrm{MT} \text {. This change ships the two } \\
\text { highest burnup capsules to ORNL for PIE, and continues the } \\
\text { irradiation of the three lowest burnup capsules unitl they } \\
\text { approach, but do not exceed } 30 \mathrm{GWd} \text { MT. This DAR changes } \\
\text { the configuration, but not the technical justifications. }\end{array}$} & $\begin{array}{l}\text { The technical justification of the original } \\
\text { ESAP permits iradiation of individual MOX } \\
\text { capsules up to a bumup of } 30 \mathrm{GWd} / \mathrm{MT} \text {. The } \\
\text { technical justification is unchanged. }\end{array}$ \\
\hline 2 & & \multicolumn{2}{|c|}{$\begin{array}{l}\text { The ESAP was updated to reference and reflect the latest } \\
\text { version of the ATR TSR's (Issue 4, Rev. } 3 \text { dated UPDATE 1998) } \\
\text { and the ATR UFSASR (Rev. 1999-AU, dated July 1, 1999) }\end{array}$} & \\
\hline & & & \\
\hline & & & \\
\hline & & & \\
\hline \multicolumn{5}{|c|}{$\begin{array}{l}\text { 8. Is this a minor document change? (See instructions for definitions.) } \\
\text { (and to block } 13 \mathrm{a} \text { if the change affects a NRC licensed facility). }\end{array}$} \\
\hline \multirow{2}{*}{$9 a$} & $\begin{array}{l}\text { roposal approval: } \bar{Z} \\
\text { rejected, indicate } \mathrm{r}\end{array}$ & $\begin{array}{l}\text { Accepted } \square \text { Deferred } \square \text { Rejected } \\
\text { eason. }\end{array}$ & \multirow{2}{*}{ Printed name: R. C.P } & edersen \\
\hline & $\begin{array}{l}\text { oes the proposal re } \\
\text { 3571? }\end{array}$ & 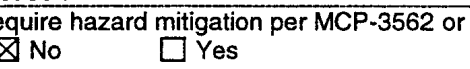 & & 11 \\
\hline
\end{tabular}

10. Actual action (if different from proposed

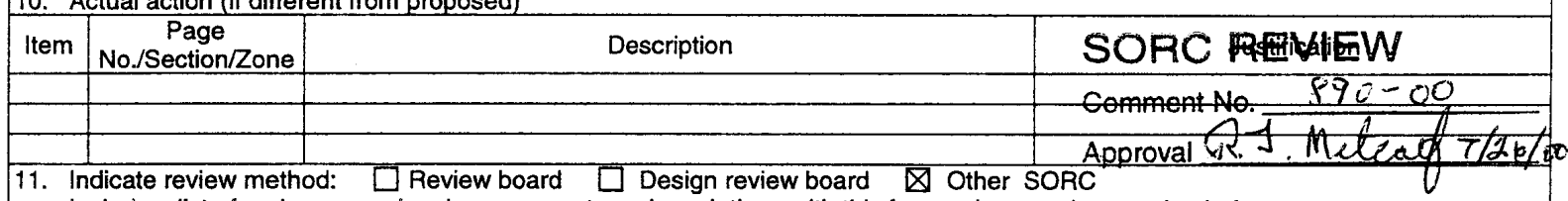

Printed Name

S. T. KHERICHA

R. C. PEDERSEN

T. A. TOMBERLIN

J. L. GREGORY

\begin{tabular}{c|c|}
\hline Discipline & Org No
\end{tabular}

PRA
PROJECT MANAGER
TRA NUCLEAR ENG.

TRA NUCLEAR ENG. SORC

12. Is document a TPR, EAR, or EPI procedure? $\square$ No $\square$ Yes If yes, indicate procedure validation method used: $\square$ formal walkdown $\square$ tabletop analysis $\square$ limited trial use/field use $\square$ partial validation $\square$ N/A (minor change)

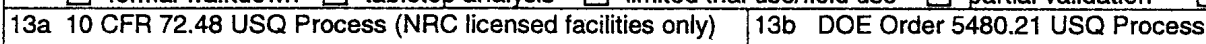

$\triangle$ Not required - See MCP-2925

Screening Results (Attach form 431.48)

If yes, Evaluation Results (Attach form 431.49)

Printed name:

Signature:

10 CFR 72.48 Qualified Screener Date

14. $\triangle$ Change does not affect a permitted area and does not affect a TSD facility. RCRA evaluation is not required.

Is RCRA permit/application modified?

$\triangle$ No $\square$ Yes $\square$ Unknown

If yes or unknown, attach or reference completed form ADE on halai.. $\square$ Not required-Categorically excluded by PRD-113 or minor document change or already screened elsewhere. Screening form attached?

$\square$ Yes No

Screening Results:

If yes, Evaluation Results

$\square$ Yes $\square$ No

(Attach form 431.20\% equivglent)

Printed name:

Signature:

Printed name:R. C. PEDERSEN

Page 1 

DOCUMENT ACTION REQUEST (DAR)

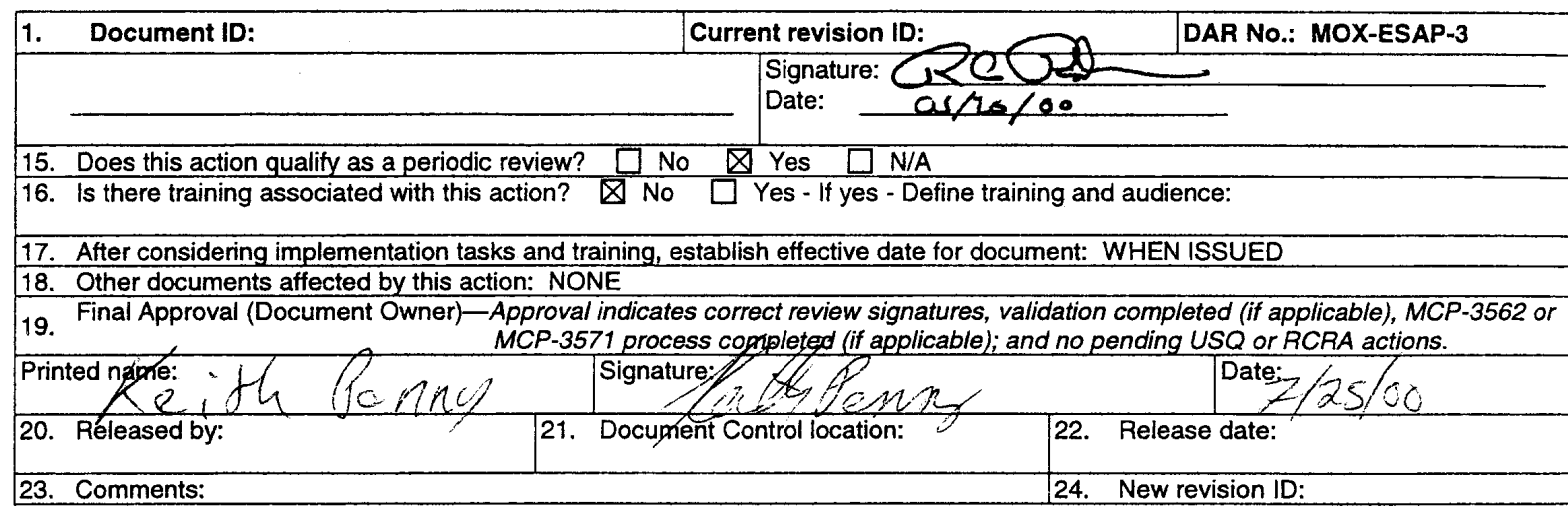

